\title{
New insights into Escherichia coli metabolism: carbon scavenging, acetate metabolism and carbon recycling responses during growth on glycerol
}

\author{
Karla Martínez-Gómez ${ }^{1}$, Noemí Flores ${ }^{1 *}$, Héctor M Castañeda ${ }^{1}$, Gabriel Martínez-Batallar ${ }^{3}$, \\ Georgina Hernández-Chávez ${ }^{1}$, Octavio T Ramírez², Guillermo Gosset ${ }^{1}$, Sergio Encarnación ${ }^{3}$ and Francisco Bolivar ${ }^{1}$
}

\begin{abstract}
Background: Glycerol has enhanced its biotechnological importance since it is a byproduct of biodiesel synthesis. A study of Escherichia coli physiology during growth on glycerol was performed combining transcriptionalproteomic analysis as well as kinetic and stoichiometric evaluations in the strain JM101 and certain derivatives with important inactivated genes.

Results: Transcriptional and proteomic analysis of metabolic central genes of strain JM101 growing on glycerol, revealed important changes not only in the synthesis of MglB, LamB and MalE proteins, but also in the overexpression of carbon scavenging genes: $/ a m B$, malE, $m g / B, m g / C$, galP and glk and some members of the RpoS regulon ( $p f k A, p f k B, f b a A, f b a B, p g i, p o x B, a c s, a c t P$ and $a c n A$ ). Inactivation of rpoS had an important effect on stoichiometric parameters and growth adaptation on glycerol. The observed overexpression of poxB, pta, acs genes, glyoxylate shunt genes ( $a c e A, a c e B, g / c B$ and $g / c C$ ) and $a c t P$, suggested a possible carbon flux deviation into the PoxB, Acs and glyoxylate shunt. In this scenario acetate synthesized from pyruvate with PoxB was apparently reutilized via Acs and the glyoxylate shunt enzymes. In agreement, no acetate was detected when growing on glycerol, this strain was also capable of glycerol and acetate coutilization when growing in mineral media and derivatives carrying inactivated poxB or pckA genes, accumulated acetate. Tryptophanase A (TnaA) was synthesized at high levels and indole was produced by this enzyme, in strain JM101 growing on glycerol. Additionally, in the isogenic derivative with the inactivated thaA gene, no indole was detected and acetate and lactate were accumulated. A high efficiency aromatic compounds production capability was detected in JM101 carrying pJLBaroG ${ }^{f b r}$ tktA, when growing on glycerol, as compared to glucose.

Conclusions: The overexpression of several carbon scavenging, acetate metabolism genes and the absence of acetate accumulation occurred in JM101 cultures growing on glycerol. To explain these results it is proposed that in addition to the glycolytic metabolism, a gluconeogenic carbon recycling process that involves acetate is occurring simultaneously in this strain when growing on glycerol. Carbon flux from glycerol can be efficiently redirected in JM101 strain into the aromatic pathway using appropriate tools.
\end{abstract}

\footnotetext{
* Correspondence: noemi@ibt.unam.mx

'Departamento de Ingeniería Celular y Biocatálisis, Instituto de Biotecnología, Universidad Nacional Autónoma de México (UNAM), Apdo. Postal 510-3,

Cuernavaca, Morelos CP 62250, Mexico

Full list of author information is available at the end of the article
} 


\section{Background}

Escherichia coli is capable of utilizing several compounds as carbon sources. However, glucose is the preferred carbon source and its rapid utilization depends on the phosphoenolpyruvate: carbohydrate phosphotransferase system (PTS). PTS not only transports specific sugars but also in the absence of its substrates, stimulates, through adenylate cyclase (Cya), the production of $c$ AMP which in turn activates the transcription of many cAMP-CRP dependent catabolic genes, including those involved in glycerol utilization [1]. Glycerol, an energy-poor carbon source, has enhanced its biotechnology importance as carbon source since it is a byproduct of the biodiesel synthesis, whose production is expected to increase in the future [2-4]. A balanced aerobic growth on glycerol depends on three global regulators: $c$ AMP-CRP as the principal inducer of the glycerol catabolic regulon (including $g l p F, g l p K$ and $g l p D$ ); Cra (FruR) as regulator of some gluconeogenic genes, and ArcA as regulator of several central metabolic genes including the TCA cycle and others involved in respiration $[1,5]$. E. coli growing aerobically on glycerol incorporates this molecule into central metabolism as dihydroxyacetone phosphate (DHAP), a metabolite which can participate in both gluconeogenic and glycolytic processes (Figure 1) [6]. The expression of metabolic genes, in particular the overexpression of $p y k A, p c k A, \operatorname{glt} A$, fum $A B C$, $s d h, m d h$ and $a c n A$ genes and the downregulation of the ack $A$ gene, has been reported for $E$. coli growing on glycerol [7]. Proteomic and enzymatic assay studies, in which cells were grown on a complete medium (Luria broth) plus glycerol, reported overexpression of the $f b p$ gene and at lower levels aceBA operon [8]. However, studies on the carbon stress response of $E$. coli growing only on an energy-poor carbon source such as glycerol are scarce. It is know that $E$. coli displays carbon stress responses when growing under carbon source limitation similar to those encountered during stationary phase or glucose limited conditions in chemostats cultures $[9,10]$, fed batch cultures [11], or in strains with limited glucose transport capabilities [12,13]. E. coli carbon stress response utilizes mechanisms which are part of the general stress response, and involve several changes in cellular physiology. This response can be a fast emergency strategy or a long-term program of adaptation to starvation [14]. The master regulator of the general stress response is the sigma factor RpoS, whose regulation is complex and involves transcriptional and posttranscriptional control mechanisms. For example, rpoS transcription is stimulated by downshifts in the specific growth rate $(\mu)[9,15,16]$. Furthermore, a continuous reduction in $\mu$, results in an inversely correlated increase in rpoS transcription (5 to 10- fold). In addition, when an abrupt cessation of growth occurs, as in response to sudden glucose starvation, rpoS transcription is also induced $[17,18]$. In strains lacking PTS which grow slowly on glucose as the sole carbon source, cells apparently sense low levels of carbon and induce rpoS transcription and several other genes involved in carbon scavenging, as well as a carbon (acetate) recycling mechanism [12,13,19-21]. Since rpoS expression is induced by different stresses, genes whose transcription are regulated by this sigma factor can be modulated by various coregulators such as $\mathrm{Crl}$. $\mathrm{Crl}$ responds to indole as a signal molecule, increasing gene transcription of some genes by binding to RpoS. This in turn, stimulates RNA polymerase holoenzyme formation [22]. Carbon stress responses also involve amino acid starvation conditions in which ppGpp concentration increases rapidly to the millimolar range. When cells are growing under stress conditions, including slow growth on glucose, the expression of central metabolic genes is modified by altering the transcription of genes that redirect metabolism [12-14,19-21].

In this report some non described features detected in E. coli strain JM101 [23] grown in minimal medium on glycerol as the sole carbon source, are presented. Gene transcription levels and protein production patterns corresponding to a carbon stress response were detected. Overexpression of genes involved in the production and consumption of acetate that correlated with no detection of this metabolite in cultures of JM101 grown on glycerol, as well as the capability of acetate and glycerol coutilization in mineral media cultures were also detected in this strain, in agreement with a "carbon stress acetate recycling" response. Additionally, derivative strains with inactivated important genes such as rpoS and some members of the PEP-PYR node ( $p c k A$, poxB, $p p c, p y k A$ and $p y k F$ ) were constructed and evaluated to clear the role of their coded proteins in the JM101 glycerol metabolism.

\section{Results and discussion}

\section{Growth of strain JM101 on different carbon sources}

Strain JM101 was grown on different carbon sources to compare its metabolic capacities. As shown in Table 1 and Figure 2, when this strain was grown on glucose, a high $\mu$ was obtained $\left(0.69 \mathrm{~h}^{-1}\right)$ and acetate was produced. When glycerol was used as the sole carbon source, its $\mu$ decreased to $0.49 \mathrm{~h}^{-1}$ and no acetate was detected (Table 1, Figure 2A). Low levels or no acetate production also have been detected in other $E$. coli strains grown on glycerol $[7,8]$. When both glucose and glycerol were present as carbon sources, as expected a diauxic response was obtained in JM101. Glucose was utilized first and glycerol was used after glucose had been completely depleted; however, less acetate was produced when this strain was grown on a mixture of these two carbon sources (Table 1, Figure 2B), suggesting that part of the 


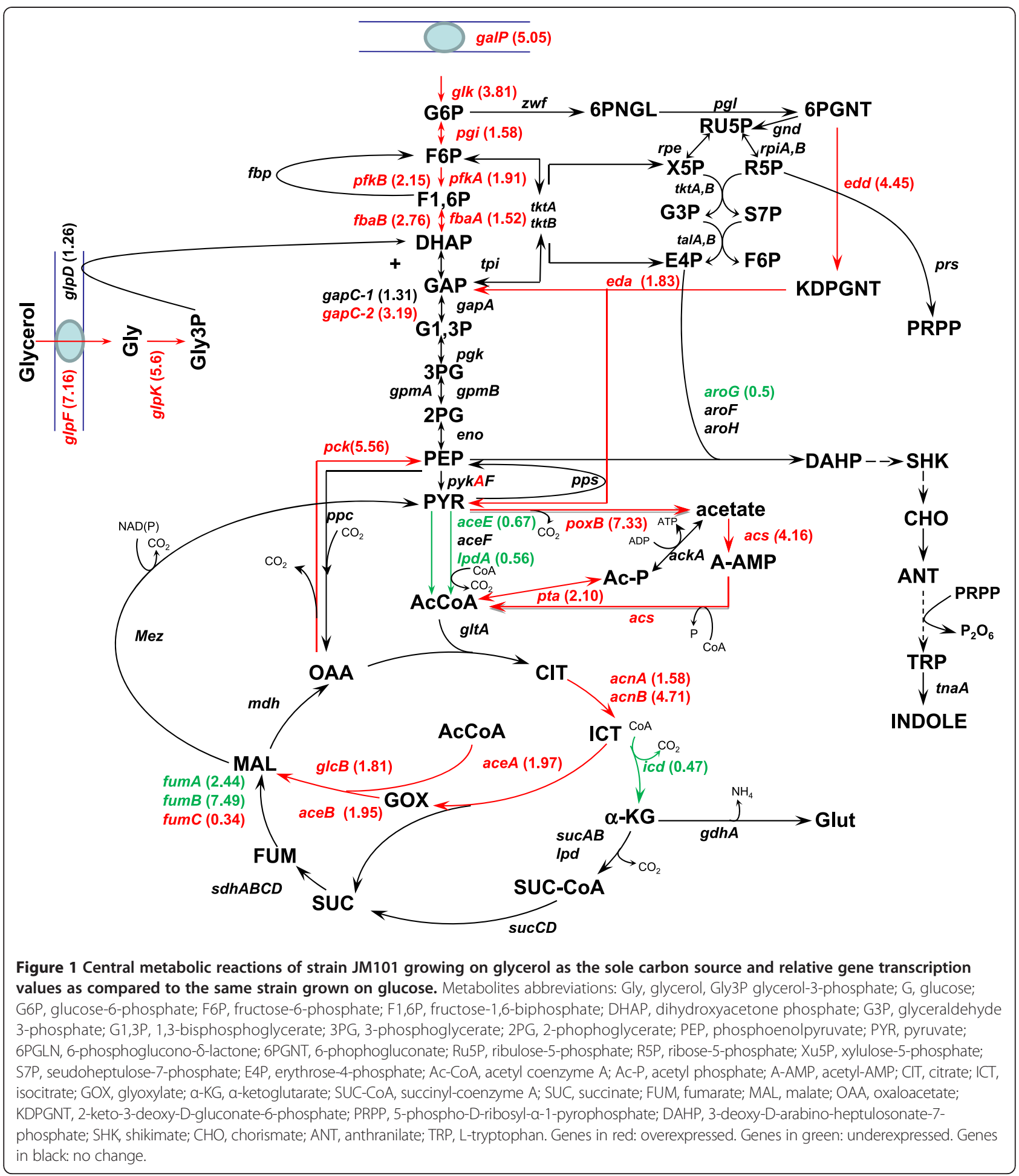

acetate produced when growing on glucose as the sole carbon source, was utilized when both substrates were present in the medium. JM101 utilized glucose and accumulated acetate when grown with a mixture of glucose and acetate as carbon sources (Figure 3A). In contrast, when a mixture of glycerol and acetate was used,
JM101 coutilized both carbon sources (Table 1, Figure 3B).

\section{Grown on glycerol of different JM101 derivatives}

The absence of acetate production in strain JM101 growing on glycerol suggested that in this strain production and 
Table 1 Specific growth rates $(\mu)$ and stoichiometric parameters of strain JM101 grown on single or mixtures of carbon sources

\begin{tabular}{|c|c|c|c|c|}
\hline Condition & $\mu\left(h_{-1}\right)$ & $\mathrm{Y}_{\mathrm{x} / \mathrm{s}}(\mathrm{g} / \mathrm{mmolC})$ & qs (mmolC/gdcw h) & $\begin{array}{l}\text { mmolc of acetate } \\
\text { produced }(+) \text { or } \\
\text { consumed }(-)\end{array}$ \\
\hline Glucose & 0.69 & 0.013 & 51.8 & +28.2 \\
\hline Glycerol & 0.49 & 0.014 & 34.3 & Not detected \\
\hline Glucose + glycerol & $0.72(0.45)$ & $0.017(0.006)$ & 43.1 & +4.1 \\
\hline Glycerol + acetate & 0.43 & 0.011 & 39.5 & -11.0 \\
\hline Glucose + acetate & $0.72(0.1)$ & $0.013(0.017)$ & $55.4(6.55)$ & +6.0 \\
\hline
\end{tabular}

Mean values from at least three independent cultures are presented. Differences between values in these experiments were $<10 \%$. The numbers in parentheses indicate data for the specific strain in those stages in which only the remaining carbon source was available.

consumption of acetate occurred simultaneously, as has been reported in strains derived from JM101 lacking PTS that grow slowly on glucose. In these derivatives where the glycolytic metabolism is apparently functioning, the gluconeogenic metabolism is induced and glucose and acetate are utilized simultaneously $[12,13,19,21,24]$. These results indicate that growth on glycerol of strain JM101 could activate some important gluconeogenic genes like poxB and $p c k A$ involved in carbon (acetate) recycling. Therefore, JM101 derivatives were constructed with inactivated key genes including rpoS, poxB and $p c k A$ (see Methods), in order to evaluate the role of their coded proteins in the glycerol fermentation, testing the effects on $\mu, \mathrm{q}_{\mathrm{s}}$ (glycerol specific rate consumption), and $Y_{x / s}$ (biomass/substrate yield), when growing in mineral medium with glycerol or glucose as the sole carbon source.
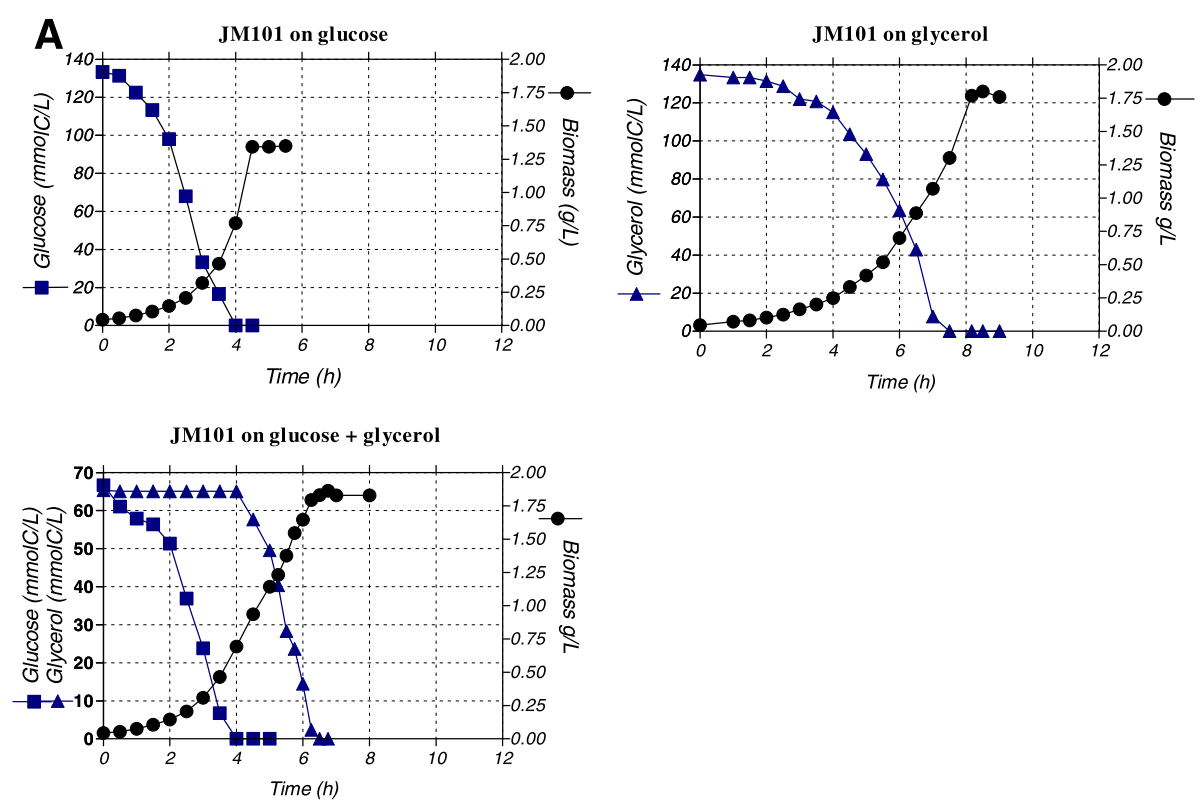

B

JM101

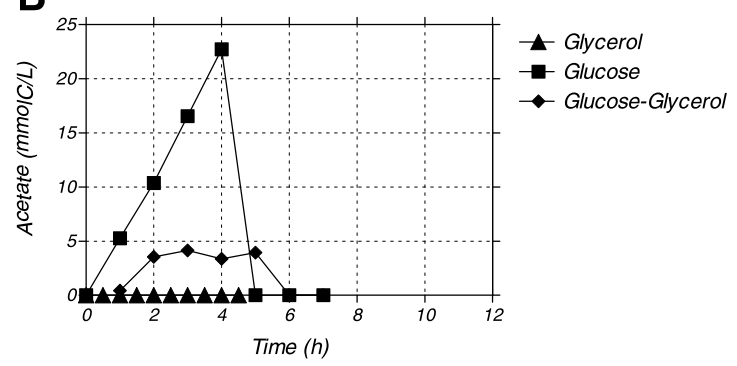

Figure 2 A) Growth profiles and substrate utilization (mmolC/L) of strain JM101 grown on glucose or glycerol and in the mixture glucose plus glycerol. B- Acetate levels (mmolC/L) of strain JM101 grown on glucose, or glycerol and on a mixture of glucose plus glycerol. 

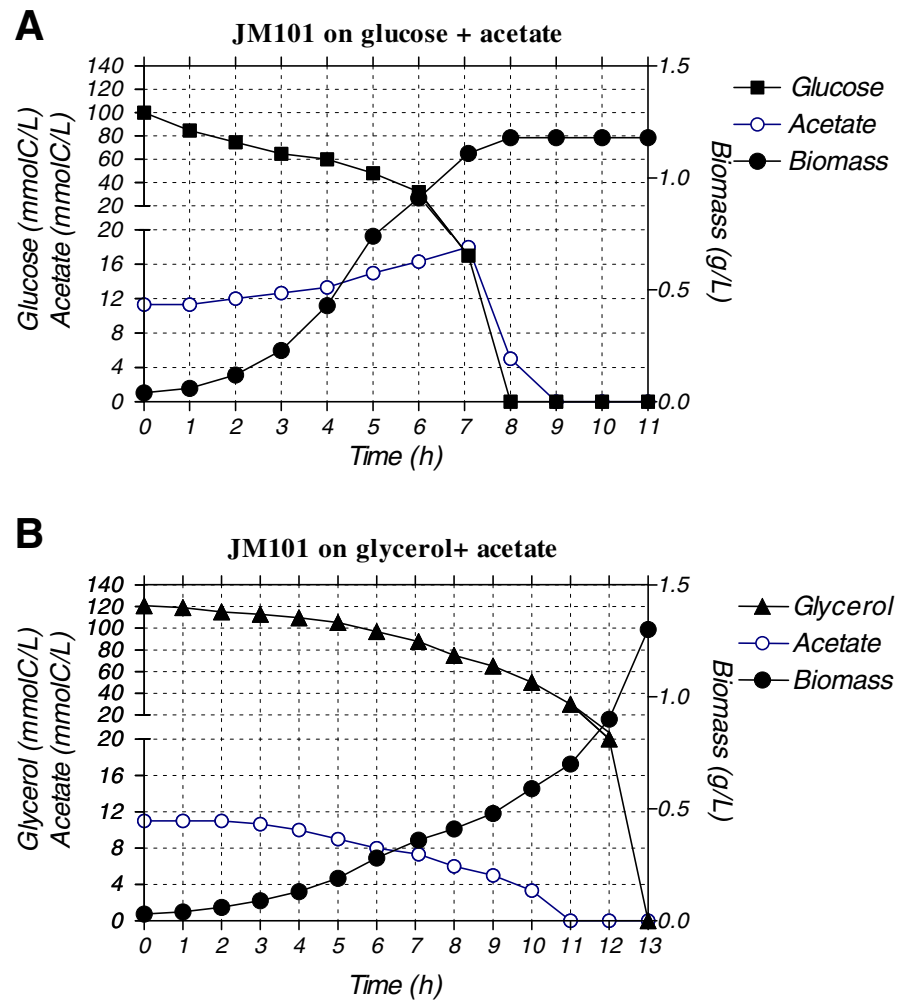

Figure 3 Biomass and acetate consumption profiles (mmolC/L) of strain JM101 grown on a mixture of glucose plus acetate (A) and on a mixture of glycerol plus acetate (B).

The JM101 $\operatorname{rpoS}$ derivative had a two-hour delay for growing in mineral media with glycerol (data not shown) and once adapted, the $\mu$ was $10 \%$ slower than the parental strain (Table 2A). This delay was not observed in the derivative growing with glucose (data not shown), which had a lower $\mathrm{q}_{\mathrm{s}},(28 \%)$ and a higher $\mathrm{Y}_{\mathrm{x} / \mathrm{s}}(23 \%)$ as compared to strain JM101 (Table 2B). RpoS is not directly involved in the expression of the genes that incorporate glycerol in the central metabolism ( $g l p F, g l p D$ and $g l p K)$; however, its relation with $g l p D$ is apparently indirect through ArcAB. Some reports argue a feedback loop, RpoS-mediated stationary phase induction of the $\operatorname{arc} A$ gene [25]. It has been reported that RpoS regulates the expression of poxB and other catabolic genes involved in carbon stress responses $[12,20,26]$. Therefore, it appears that RpoS, the master regulator of the stress response, is important for adapting and maintaining an adequate balanced growth on glycerol as the sole carbon source in mineral media, as compared to the strain grown on glucose (Tables $2 \mathrm{~A}-\mathrm{B}$ ).

The JM101 $\operatorname{pox} B$ derivative had the same $\mathrm{q}_{\mathrm{s}}$ and $\mathrm{Y}_{\mathrm{x} / \mathrm{s}}$ as the parental strain but its $\mu$ was also reduced $10 \%$ and accumulated acetate in the culture, when growing on glycerol (Table 2A). This result can be explained in two ways: poxB inactivation could be responsible for acs underexpression and/or could indicate that utilization of PYR through PoxB to produce acetate and the concomitant reduction of quinones at the membrane [18], could be necessary for the complete induction of the glyoxylate shunt (Figure 1). Additional evidence supporting PoxB involvement in acetate utilization when glycerol is utilized as unique carbon source, is presented in the next section, where the overexpression of $\operatorname{pox} B$, acs, aceBA genes is presented and discussed. Nevertheless it is important to notice that the JM101 $\Delta r p o S$ derivative did not accumulate acetate which is in fact produced in the JM101 $\Delta$ poxB derivative. RpoS as mentioned is involved in the expression of carbon stress genes including poxB. Therefore, it appears that as has been proposed poxB and other members of the RpoS regulon could be transcribed also by RpoD, the vegetative sigma factor, in certain grown conditions, including slow grown on glucose [12,18-20] and in agreement with these results, maybe in glycerol fermentation. In the absence of RpoS, poxB could be transcribed by RpoD, explaining the absence of acetate in JM101 $\Delta$ rpoS 
Table 2 Specific growth rates $(\mu)$ and stoichiometric parameters of strain JM101 and derivative mutants grown on glycerol (A) and glucose as carbon source (B)

\begin{tabular}{|c|c|c|c|c|}
\hline \multicolumn{5}{|l|}{ A) } \\
\hline Strain & $\mu\left(h^{-1}\right)$ & $Y_{x / s}(g / m m o l C)$ & $q_{s}(\mathrm{mmolC} / g d c w ~ h)$ & Acetate $(g / L)$ \\
\hline JM101 & $0.49(+/-0.02)$ & $0.014(+/-0.001)$ & $34.6(+/-1.90)$ & No detected \\
\hline $\mathrm{JM101} \Delta p c k A$ & $0.45(+/-0.03)$ & $0.014(+/-0.001)$ & $33.3(+/-4.56)$ & $0.12(+/-0.01)$ \\
\hline JM101 $\Delta p o x B$ & $0.44(+/-0.01)$ & $0.014(+/-0.001)$ & $35.5(+/-2.14)$ & $0.12(+/-0.01)$ \\
\hline $\mathrm{JM} 101 \Delta p p c$ & No growth & & & \\
\hline JM101 & $0.46(+/-0.02)$ & $0.015(+/-0.001)$ & $30.3(+/-0.12)$ & Not detected \\
\hline JM101 $\Delta p y k F$ & $0.46(+/-0.02)$ & $0.014(+/-0.002)$ & $31.4(+/-1.00)$ & Not detected \\
\hline JM101 & $0.44(+/-0.02)$ & $0.018(+/-0.002)$ & $24.8(+/-2.57)$ & Not detected \\
\hline \multicolumn{5}{|l|}{ B) } \\
\hline Strain & $\mu\left(h^{-1}\right)$ & $Y_{x / s}(g / m m o l C)$ & $q_{s}(\mathrm{mmolC} / g d c w ~ h)$ & Acetate $(g / L)$ \\
\hline JM101 & $0.69(+/-0.03)$ & $0.013(+/-0.001)$ & $51.8(+/-2.22)$ & $0.5(+/-0.01)$ \\
\hline $\mathrm{JM101} \Delta p c k A$ & $0.62(+/-0.09)$ & $0.023(+/-0.011)$ & $50.7(+/-16.82)$ & $0.7(+/-0.02)$ \\
\hline$J M 101 \Delta p o x B$ & $0.68(+/-0.04)$ & $0.014(+/-0.002)$ & $50.7(+/-2.50)$ & $0.4(+/-0.02)$ \\
\hline $\mathrm{JM} 101 \Delta p p c$ & No growth & & & \\
\hline JM101 & No determinated & No determinated & No determinated & \\
\hline JM101 & No determinated & No determinated & No determinated & \\
\hline JM101_rpos & $0.71(+/-0.01)$ & $0.013(+/-0.004)$ & $54.5(+/-8.34)$ & $0.5(+/-0.01)$ \\
\hline
\end{tabular}

[20]. In JM101 $\triangle p o x B$ acetate is produced indicating the necessity of PoxB in acetate recycling metabolism. An alternatively not exclusive explanation for the absence of acetate in JM101 $\operatorname{rppoS}$ is that in this derivative, a lower glycerol specific consumption occurred which could be responsible of less PEP production which is sensed as a low carbon flux that in turn induces carbon reutilization.

The JM101 $\Delta p c k A$ derivative had $2 \mathrm{~h}$ adaptation time for growing in mineral media as compared to the parental strain JM101 (data not shown), accumulated acetate during fermentation and the $\mu$ was reduced about $10 \%$ when growing on glycerol. However, the $\mathrm{q}_{\mathrm{s}}$ and $\mathrm{Y}_{\mathrm{x} / \mathrm{s}}$ values were not substantially affected in this mutant strain (Table 2A). PckA appears to be important for glycerol utilization and also for completing a gluconeogenic cycle to prepare strain JM101 to grow in a gluconeogenic substrate such as acetate. Production of acetate in this mutant also indicates that carbon flux through PckA could be important to maintain ATP/ ADP levels, since it has been reported that overexpression of $p c k A$ enhances ATP intracellular levels [27] (Figure 1). This proposal is supported by transcription results presented in the next section, where overexpression of $p c k A$ is presented and discussed.

The derivative carrying the $p p c$ gene inactivated was incapable of growing on glycerol or glucose as the sole carbon sources (Tables $2 \mathrm{~A}-\mathrm{B}$ ), indicating that $\mathrm{Ppc}$ is essential to grow in these two carbon sources, and cannot be replaced by the Pyk enzymes (Figure 1) and PEP has to be converted directly into OAA using Ppc to allow growth on glucose or glycerol as sole carbon sources. Similar results have been reported by others [28-31].

Derivatives carrying $p y k A$ or $p y k F$ inactivated genes did not substantially modify the specific growth rates as compared to the parental strain, when growing on glycerol as the sole carbon source (Table 2A).

\section{Differential transcription of genes and coded proteins} production in the strain JM101 grown on glycerol, as compared to glucose

\section{Glycerol uptake}

Glycerol is converted into DHAP by a process of uptake (GlpF), phosphorylation (GlpK), and dehydrogenation (GlpD) (Figure 1). As expected, $g l p F$ and $g l p K$ were overexpressed in strain JM101 grown on glycerol (Table 3). In agreement, the protein products of these genes, GlpK (16.18X) and GlpD (5.18X) -involved in the transformation of glycerol into glycerol-3-phosphate (Gly3P) and this metabolite into DHAP, respectively- were overproduced in this strain (Table 4). Surprisingly, the expression of $g l p D$ was not substantially modified (Table 3, Additional file 1). Interestingly, the transcription of $g l p F$ and $g l p K$ is regulated by CRP and GlpR, whereas the expression of $g l p D$ is regulated by CRP, GlpR and ArcA, as proposed elsewhere $[1,5]$.

\section{Glucose and other carbohydrate scavengers}

Strain JM101 grown on glycerol overexpressed, as compared to the expression values grown on glucose, several genes of the mal/lam and $\mathrm{mgl} / \mathrm{gal}$ regulons: 
Table 3 Relative transcription levels determined by RT-qPCR of several group of genes from strain JM101 on glycerol as the only carbon source

\begin{tabular}{|c|c|c|}
\hline Glycolysis & $\begin{array}{l}\text { Gluconeogenic, } \\
\text { anaplerotic and } \\
\text { glyoxylate shunt }\end{array}$ & TCA cycle \\
\hline aceE $0.67+/-0.17$ & aceA 1.97 +/- 0.39 & $a c n A$ 1.58+/- 0.26 \\
\hline acef $0.80+/-0.22$ & aceb $1.95+/-0.06$ & $a c n B \quad 4.71+/-0.47$ \\
\hline eno 0.86 +/- 0.12 & ackA $1.49+/-0.28$ & fumA $2.44+/-0.45$ \\
\hline fbaA $1.52+/-0.09$ & $\operatorname{acs} 4.16+/-0.34$ & fumB $7.49+/-0.40$ \\
\hline$f b a B 2.76+/-0.22$ & $f b p 1.51+/-0.10$ & fumc $0.34+/-0.10$ \\
\hline gapA $0.72+/-0.06$ & g/cB $1.81+/-0.56$ & gltA $0.76+/-0.02$ \\
\hline$g a p c-1 \quad 1.31+/-0.10$ & g/cC $1.81+/-0.28$ & icd $0.47+/-0.10$ \\
\hline$g a p c-2 \quad 3.19+/-0.67$ & maeB 1.23 +/- 0.01 & mdh $0.65+/-0.10$ \\
\hline glk $3.81+/-0.14$ & pckA $5.56+/-1.77$ & sdhA 1.04+/- 0.01 \\
\hline gpmA $0.90+/-0.09$ & poxB $7.33+/-0.56$ & $s d h B 1.37+/-0.42$ \\
\hline IpdA $0.56+/-0.05$ & ppc $1.11+/-0.14$ & $s d h C 0.92+/-0.05$ \\
\hline pfkA $1.91+/-0.22$ & pta $2.10+/-0.23$ & $s d h D 1.13+/-0.21$ \\
\hline pfkB $2.15+/-0.01$ & ppsA $1.26+/-0.22$ & SUCA $0.81+/-0.13$ \\
\hline pgi $1.58+/-0.37$ & sfcA $2.05+/-0.34$ & sucB $0.80+/-0.23$ \\
\hline pgk $1.08+/-0.13$ & & succ $0.79+/-0.07$ \\
\hline pykA $1.77+/-0.10$ & & sucD 1.36+/- 0.13 \\
\hline \multicolumn{3}{|l|}{ pykF $0.98+/-0.09$} \\
\hline \multicolumn{3}{|l|}{ tpi $1.36+/-0.10$} \\
\hline $\begin{array}{l}\text { Pentose phosphate } \\
\text { Entner-Doudoroff }\end{array}$ & Glycerol uptake & $\begin{array}{l}\mathrm{mal} / \mathrm{lam} \text { and } \\
\mathrm{mgl} / \mathrm{gal} \text { regulons }\end{array}$ \\
\hline eda $1.83+/-0.29$ & glpF $7.16+/-0.15$ & galp $5.05+/-0.26$ \\
\hline edd $4.45+/-0.29$ & glpK $5.60+/-0.87$ & galR $0.38+/-0.13$ \\
\hline gnd $0.80+/-0.00$ & glpD $1.26+/-0.25$ & gals $0.57+/-0.01$ \\
\hline talA 1.64+/-0.47 & $g / p R 2.40+/-0.06$ & galt $0.49+/-0.00$ \\
\hline talB $0.60+/-0.01$ & & $\operatorname{lamB} 1.36+/-0.30$ \\
\hline tktA 1.22+/-0.06 & & $m g / B 5.05+/-0.58$ \\
\hline tktB $0.70+/-0.11$ & & $\mathrm{mg} / \mathrm{C} 2.28+/-0.12$ \\
\hline \multirow[t]{2}{*}{ zwf $1.34+/-0.04$} & & male $1.77+/-0.20$ \\
\hline & & pgm 2.37+/-0.62 \\
\hline $\begin{array}{l}\text { Aromatic } \\
\text { pathway }\end{array}$ & $\begin{array}{l}\text { Respiration, } \\
\text { transhydrogenases }\end{array}$ & $\begin{array}{l}\text { Transporters/ } \\
\text { porins }\end{array}$ \\
\hline $\operatorname{aroA} 0.81+/-0.03$ & frdA 1.58+/-0.15 & actP $13.49+/-1.31$ \\
\hline $\operatorname{aroB} 1.98+/-0.59$ & $\operatorname{frdB} 1.73+/-0.11$ & $\operatorname{aro} P 1.61+/-0.00$ \\
\hline $\operatorname{aroc} 1.34+/-0.02$ & frdC $4.68+/-0.21$ & shiA $0.75+/-0.02$ \\
\hline $\operatorname{aroD} 3.29+/-0.07$ & frdD $2.01+/-0.34$ & $\mathrm{ompC} 0.17+/-0.01$ \\
\hline $\operatorname{arot} 5.47+/-0.16$ & pntA $0.69+/-0.03$ & ompF $1.17+/-0.21$ \\
\hline arof $1.32+/-0.08$ & udhA 4.89+/-0.88 & \\
\hline \multicolumn{3}{|l|}{$\operatorname{arog} 0.50+/-0.13$} \\
\hline \multicolumn{3}{|l|}{$\mathrm{aroH} 1.36+/-0.13$} \\
\hline \multicolumn{3}{|l|}{ arok $1.01+/-0.07$} \\
\hline aroL $2.48+/-0.09$ & & \\
\hline
\end{tabular}

Table 3 Relative transcription levels determined by RT-qPCR of several group of genes from strain JM101 on glycerol as the only carbon source (Continued)

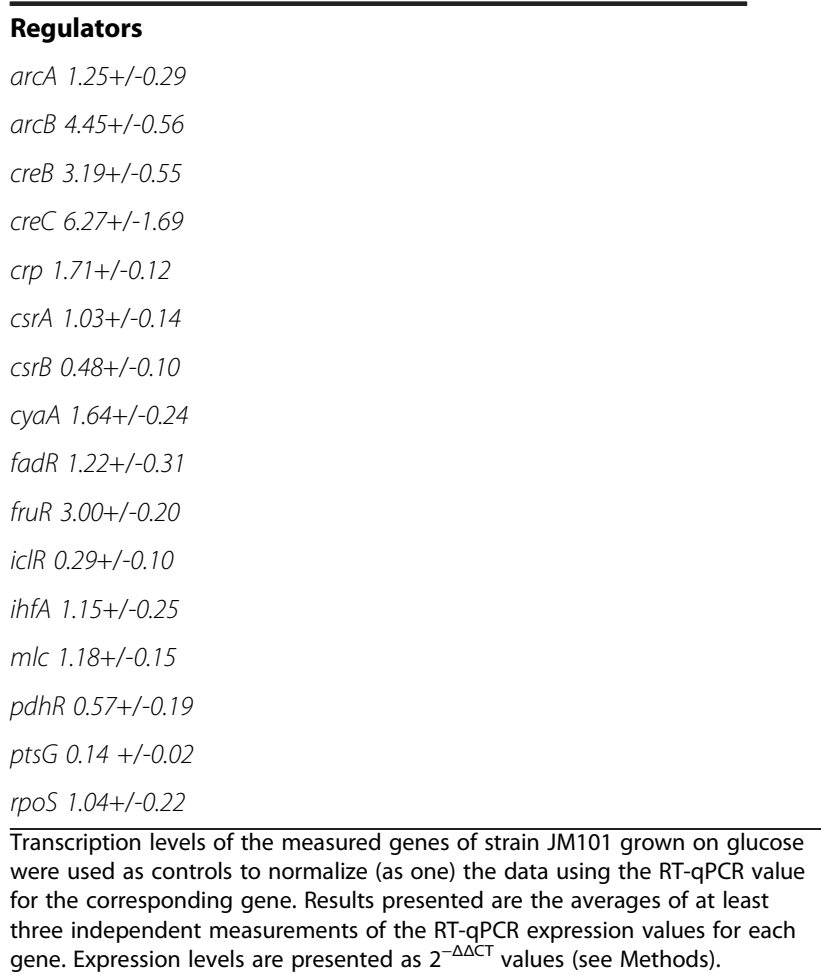

lamB, malE, mglB, mglC, galP, glk and pgm (Table 3, Additional file 1). As shown in Table 4, the products of some of these genes, MglB (81.02X), LamB (6.94X) and MalE (7.06X) were produced at higher concentrations in the strain grown on glycerol. The mal/lam system in E. coli contains genes involved in transport and catabolism of maltose or maltodextrins [32-34] and the $\mathrm{mgl} / \mathrm{gal}$ system contains genes related to the transport ( $\mathrm{galP}$ and $\mathrm{mglBAC}$ ) and amphibolic utilization (galETKM) of D-galactose [34-36]. In E. coli, the induction of both regulons has been reported as a response to growth at low glucosecarbon conditions such as those encountered in chemostats at low dilution rates or in starving cells [9,10,34-37]. Also, strains with limited glucose transport capacity growing slowly on this carbohydrate, such as those lacking PTS, overexpress the mal/lam and $\mathrm{mgl} / \mathrm{gal}$ regulons, in a "nutrient scavenging stress response" $[10,13,19]$. In these scenarios, increased expression levels of these regulons have been reported, since high levels of CAMP-CRP are detected and the synthesis of maltotriose (mal/lam) and D-galactose ( $m g l / g a l)$ as autoinducers are produced $[1,9,10,34,38]$. These results are in agreement with those reported by Liu et al. (2005) which indicate that poor carbon sources like glycerol, develops in E. coli a "carbon source foraging strategy" [37]. In strain JM101 grown on glycerol as the sole carbon source, high levels of $c$ AMP and glycogen synthesis are 
Table 4 Proteins differentially produced in strain JM101 grown on glycerol, as compared to the production on glucose

\begin{tabular}{|c|c|c|c|c|c|}
\hline Spot No. & Gene name & Protein description & Mw & $\mathrm{pl}$ & $\begin{array}{l}\text { Ratio IOD } \\
\text { glycerol/IOD } \\
\text { glucose }\end{array}$ \\
\hline B11 & $\arg G$ & Argininosuccinate synthase & 50038 & 5.23 & 0.37 \\
\hline 58 & $c d d$ & Cytidine deaminase & 31805 & 5.42 & 6.97 \\
\hline 51 & fumA & Fumarate hydratase class I & 60774 & 6.11 & 2.38 \\
\hline 57 & $m g / B$ & D-galactose-binding periplasmic protein & 35690 & 5.68 & 81.03 \\
\hline 11 & $g / p D$ & Aerobic glycerol-3-phosphate dehydrogenase & 56886 & 6.97 & 5.18 \\
\hline D11 & glpK & Glycerol kinase & 56480 & 5.36 & 16.18 \\
\hline 75 & $g \ln A$ & Glutamine synthetase & 52099 & 5.26 & 0.31 \\
\hline 60 & $\arg T$ & Lysine-arginine-ornithine-binding periplasmic protein & 28088 & 5.62 & 2.57 \\
\hline P10 & ompC & Outer membrane protein $C$ & 40343 & 4.58 & 0.32 \\
\hline 31 & male & Maltose-binding periplasmic protein & 43360 & 5.53 & 7.07 \\
\hline 27 & $\operatorname{lam} B$ & Maltoporin & 49995 & 4.81 & 6.94 \\
\hline 50 & $p c k A$ & Phosphoenolpyruvate carboxykinase [ATP] & 59891 & 5.46 & 9.17 \\
\hline 73 & ptsl & Phosphoenolpyruvate-protein phosphotransferase & 63750 & 4.78 & 0.23 \\
\hline D10 & deoD & Purine nucleoside phosphorylase deoD-type & 26161 & 5.42 & 2.08 \\
\hline 63 & gatY & D-tagatose-1,6-bisphosphate aldolase subunit & 31021 & 5.87 & 55.83 \\
\hline 62 & $u d p$ & Uridine phosphorylase & 27313 & 5.81 & 7.41 \\
\hline K10 & thaA & Tryptophanase & 53119 & 5.88 & 17.03 \\
\hline 72 & typA & GTP-binding protein TypA/BipA & 67542 & 5.16 & 0.44 \\
\hline
\end{tabular}

Spot intensities were quantified using PD Quest software 8.0.1 on three experiments. Only reproducible phenotypes, with a Student's $t$ test value $\mathrm{p} \leq 0.05$ are shown. Additional file 3 contains other important proteomic parameters.

pl: Isoelectric point.

Mw: Molecular weight.

IOD: Integrated optical density.

expected, as well as glycogen degradation to maltodextrinsglucose and D-galactose. In this strain, galT, galR and galS genes were apparently slightly underexpressed, whereas the galP gene was overexpressed (Table 3). Furthermore, the gal regulon genes are differentially regulated by cAMP-CRP and $\mathrm{D}$-galactose, and in the absence of D-galactose the expression of the $m g l B A C$ operon can be activated by cAMPCRP, whereas the transcription of galP gene is strongly repressed $[38,39]$. The inactivation of galP did not modify the $\mu$ of JM101 $\triangle$ galP grown on glycerol (data not shown), indicating that GalP is not playing an important role in glycerol transport. The malE gene and the mglBAC operon are transcribed by RpoS. In E. coli, rpoS is induced when cells are growing under stress conditions such as carbon, phosphorus, nitrogen or amino acid starvation. Therefore, RpoS apparently replaces, at least partially, the vegetative sigma factor RpoD in the transcription of certain genes when growing in glucose limited conditions $[12,19,20,37,40]$. It has been reported that the regulatory protein $\mathrm{Crl}$ increases RpoS activity by direct interaction with the RpoS holoenzyme [41]. In addition, the MalE protein is produced at low levels in E. coli $\mathrm{crl}$ or $\mathrm{crl} / \mathrm{rpoS}$ mutants, as compared to the wild type strain [41]. Therefore, it is possible that in JM101 growing on glycerol, RpoS-Crl could upregulate the expression of some members of these regulons. In JM101 grown on glycerol, the OmpC porin was produced at lower levels as compared to glucose (Table 4). The ompC gene, which was underexpressed in this condition (Table 3), has a complex regulation including protein regulators $(\mathrm{OmpR}, \mathrm{CpxR}$, Lrp, IHF and EnvY) and small regulatory RNAs (micC, rse $X$ and $r y b B$ ) that respond to different signals [42-46]. In JM101, the low expression levels of $\operatorname{ompC}$ and the low production of $\mathrm{OmpC}$ were apparently coordinated with the high production of LamB, which appears to be the principal porin when this strain was grown on this carbon source (Tables 3 and 4, Additional file 1). Since $\operatorname{lamB}$ expression level is increased when nutrients are scarce, it has been proposed that LamB can transport a wide variety of sugars such as glucose, lactose, arabinose, and even glycerol $[10,13,19,47]$. During the growth of JM101 on glycerol, it is possible that sensing of low nutrient availability or low osmolarity, compared to the growth on glucose, could be part of the signals involved in the reduced production of OmpC.

\section{Central metabolism genes \\ Glycolysis}

The glk gene, which codes for glucokinase (Glk), was overexpressed in JM101 grown on glycerol (Table 3). Glk 
phosphorylates glucose into G6P during its transport from the periplasm to the cytoplasm by GalP or MlgABC $[6,12,13,48]$. glk carries a putative RpoS promoter [20] and is apparently repressed by Cra (FruR) [49]. The pgi gene was also slightly overexpressed in this strain (Table 3); as well as in strains lacking PTS growing slowly on glucose as the only carbon source [13]. Pgi is involved in the reversible transformation of G6P into fructose-6-phosphate (F6P) (Figure 1). In the upper part of the glycolytic pathway, $p f k A$ and $p f k B$ encoding for phosphofrukinase I and II, respectively, were overexpressed (Table 3, Additional file 1). PfkA and PfkB convert F6P to fructose-1,6P (F1,6P) consuming one ATP molecule (Figure 1). These proteins are an important control point of the glycolytic flux. The $p f k A$ gene is positively regulated by CsrA [49] and has a putative RpoS promoter [20,41]. Additionally, E. coli strains inactivated in the $\mathrm{crl}$ or rpoS genes produced lower levels of PfkA as compared to the parental strain, suggesting that this gene is part of the RpoS regulon [41]. The expression of $p f k B$ is repressed by CsrA [49] and this gene has a putative promoter that could be transcribed by RpoS $[20,50,51]$. Interestingly GatY, a protein that is part of the galactitol degradation pathway, was produced at very high levels (55.83X) in this strain grown on glycerol, as compared to those on glucose (Table 4). GatY is a reversible enzyme that catalyzes the synthesis of tagatose-1,6 phosphate from DHAP and GA3P; it is regulated by CRP, ArcA and GatR. GatY overproduction apparently occurs as a growth response on glucose-limited conditions such as those found in fed batch cultures [52]. The transcripts of the gluconeogenic $f b a A$ and $f b a B$ genes, whose coded proteins are involved in the reversible transformation of DHAP and glyceraldehyde 3-phosphate (G3P) into F1,6P, were overexpressed in JM101 (Table 3). This is an important gluconeogenic step for glycerol metabolism (see below). DHAP can be transformed into G3P by TpiA (Figure 1). DAHP and G3P can be transformed into F1,6P through
FbaA and FbaB. Additionally, G3P is a key metabolite that can be utilized in several pathways including the glycolytic and pentose pathways (see below). This compound is transformed by GapA into G1,3P, which in turn is transformed into PEP through the participation of several glycolytic enzymes (Figure 1). Interestingly, the expression levels of tpiA, gapA, gpmA and $p g k$ were not substantially modified in JM101 grown on glycerol as compared to the values obtained for the growth on glucose (Table 3). E. coli has two pyruvate kinases catalyzing the conversion of PEP into PYR coupled to the synthesis of ATP. These isoenzymes, PykA and PykF, are coded by the $p y k A$ and $p y k F$ genes, respectively. This reaction is the second point of flux control in the glycolytic pathway (Figure 1). Strain JM101 slightly overexpressed the $p y k A$ gene (Table 3 ). This data is in agreement with previous reports of other E.coli strains grown on glycerol as the only carbon source $[7,8]$. The $p y k A$ and $p y k F$ genes have putative promoters that could be transcribed by $\mathrm{RpoS}$, and $p y k F$ is negatively regulated by Cra $[20,53]$. PykF is activated by F1,6P, whereas PykA is modulated by AMP and sugars of the pentose-phosphate pathway. Consequently, in conditions of low F1,6P levels as expected in cells grown on glycerol, PykA is probably the enzyme mainly utilized for growth [7]. As mentioned, single inactivation derivatives were constructed in the two genes coding for these pyruvate kinases and their growth on glycerol was evaluated. No significant differences were found in the $\mu$ of these mutants as compared to the parental strain (Table 2A). However, the total specific activity of pyruvate kinase was lower in the $p y k A$ mutant strain as compared to the strain with $p y k F$ inactivated or the parental strain (Figure 4). These results suggest that PykA was produced preferentially when JM101 was grown on glycerol and, therefore, it is apparently responsible for the main pyruvate kinase activity in vivo. Finally, PYR is utilized by the pyruvate dehydrogenase (Pdh) enzyme for the synthesis of AcCoA. The glycolytic genes, whose coded

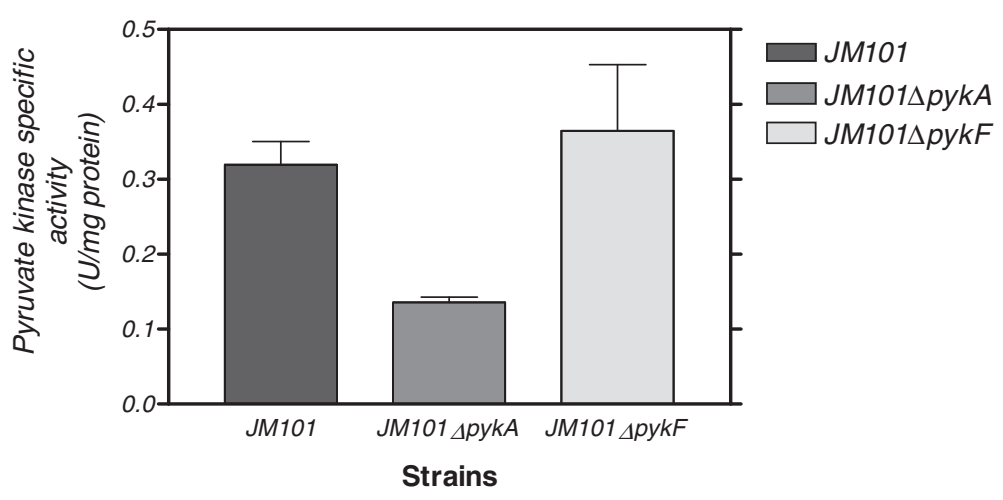

Figure 4 Specific activities of the pyruvate kinases in strains JM101 $\Delta p y k A$ and JM101 $\Delta p y k F$ respectively, grown on glycerol, as compared to the strain JM101 grown on glycerol. 
products are involved in this transformation (aceE, aceF and $\operatorname{lpd} A$ ), were slightly underexpressed in JM101 grown on glycerol, as compared to the growth on glucose (Table 3). These results clearly indicate that the glycolytic metabolism is functional in JM101 and are in agreement with a carbon flux deviation through PoxB for acetate production that has been proposed for slow-growing JM101 derivatives such as PB11 that lacks PTS [12,13,19,20], and in agreement with the overexpression of $p o x B$, acs, and the glyoxylate shunt genes in JM101 in these growing conditions $[12,13,19,20]$ (see below).

\section{The pentose pathway, Entner-Doudoroff and gluconeogenic metabolism in the upper glycolytic metabolism}

Several gluconeogenic reactions are involved in the upper glucose metabolism pathway to allow gluconeogenic metabolism and the synthesis of G6P from glycerol (Figure 1). Glycerol is incorporated as DAHP and this metabolite and G3P are transformed into F1,6P. This compound is converted to F6P, and later transformed into G6P. The $f b a A$, $f b a B$ and $f b p$ genes involved in these gluconeogenic steps were overexpressed in JM101 (Table 3, Additional file 1). Interestingly, only edd and eda corresponding to the Entner-Doudoroff pathway were overexpressed in the pentose pathway (Table 3). The product of this last gene is involved in the synthesis of G3P and PYR from 2-keto-3deoxy-D-gluconate-6-phosphate (KDPGNT) (Figure 1).

\section{Acetate pathways, anaplerotic and other gluconeogenic genes}

The poxB, acs, actP and pta genes are involved in transport, production and consumption of acetyl-phosphate
(Ac-P) and acetate (Figure 1). poxB, acs and actP are overexpressed in conditions of glucose starvation and are part of the RpoS regulon [12,25,26,54]. These genes were also overexpressed in JM101 grown on glycerol. Additionally, the overexpression of $a c e B$, ace $A$ and $g l c B$ in these growing conditions suggests the induction of the glyoxylate pathway (Table 3, Additional file 1). Since no acetate was detected during the growth of JM101 on glycerol, it is possible that a fraction of the acetate was synthesized via PoxB and in turn, this metabolite was transformed into AcCoA by Acs, apparently inducing a gluconeogenic response utilization of acetate by the glyoxylate shunt enzymes, as has been proposed for strain PB11 [11,18]. To confirm this hypothesis, strain JM101 with an inactivated poxB gene (JM101 $\Delta p o x B$ ) grown on glycerol was evaluated. This derivative accumulated acetate during fermentation and its $\mu$ was reduced $10 \%$ as compared to the parental strain (Table 2A), indicating a role of PoxB in acetate metabolism growing on glycerol as the carbon source. In agreement, the isocitrate lyase specific activity (Icl or AceA, one of the glyoxylate shunt enzyme) was detected in JM101 grown on glycerol but not on glucose as the only carbon source (Figures 1 and 5). The actP gene, which was also overexpressed is part of the acs operon, is positively regulated by CRP and can be transcribed by 54,70 and 38 (RpoS) sigma factors [12,20,24,55]. Therefore, it appears that since glycerol is a poor carbon source, part of the response involved in carbon scavenging (including acetate reutilization or recycling) is activated in this strain when growing on glycerol. In agreement, genes involved in the synthesis of pyruvate dehydrogenase were slightly underexpressed in these growing conditions, indicating

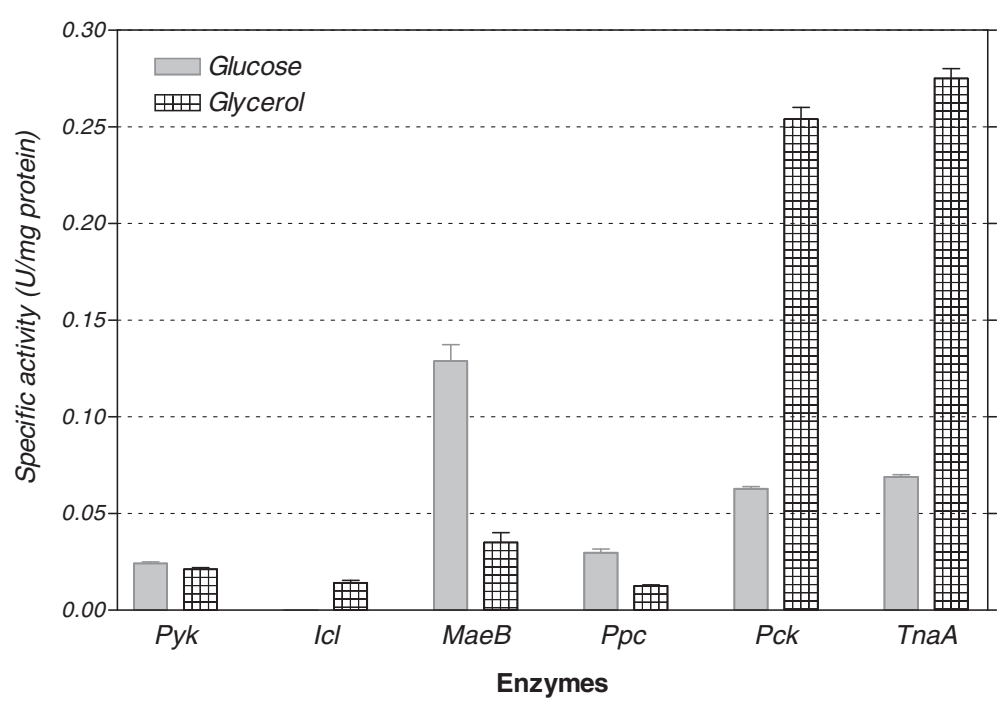

Figure 5 Specific activities of certain central metabolic enzymes of strain JM101 grown on glycerol, as compared to the same specific activities of the strain grown on glucose. 
that part of the carbon flux is apparently directed and recycled via PoxB/Acs and the glyoxylate shunt $[12,13,20,37,56,57]$. The $p c k A$ gene was also highly overexpressed and its coded protein was synthesized at high levels in JM101 (Tables 3 and 4); consequently, the PckA specific activity was higher on glycerol as compared to glucose (Figure 5). The overexpression of this gene in other $E$. coli strains grown on glycerol has been previously reported $[8,58]$. The $p c k A$ gene is regulated by Cra, and PckA synthesizes PEP from oxalacetate (OAA), with the production of ATP and $\mathrm{CO}_{2}$. OAA is an indispensable metabolite for the TCA cycle regeneration and it is precursor of aspartate (Figure 1). It appears that when glycerol is used as the sole carbon source and the proposed acetate-glyoxylate shunt and carbon recycling program is running, PckA is apparently involved in the gluconeogenic cycle. In accordance are the facts that MaeB is an enzyme that utilizes $\mathrm{NADPH}_{2}$ for converting MAL to PYR, the maeB gene was not upregulated and the specific activity of this enzyme was lower on glycerol as compared to glucose, indicating a role of PckA in the gluconeogenic pathway, in these growing conditions (Figures 1 and 5). In agreement, $p c k A$ inactivation as mentioned decreased $10 \%$ the $\mu$ of the derivative strain as compared to the parental strain (Table 2A). Interestingly and in agreement with this acetate recycling proposal, when JM101 was grown on a mixture of glycerol plus acetate, the $\mu$ of this strain was not enhanced; however, acetate was coutilized with glycerol (Table 1 and Figures 2 and 3).

\section{TCA cycle}

The $a c n A$ and $a c n B$ genes were overexpressed in strain JM101 grown on glycerol as compared to glucose (Table 3, Additional file 1). These genes code for aconitases A and B respectively, involved in the synthesis of isocitrate (ICT) from citrate (CIT) (Figure 1). The acnA gene is positively regulated by Crp, SoxRS, FNR and repressed by ArcA [59], whereas $a c n B$ is positively regulated by $\mathrm{CRP}$ and negatively regulated by ArcA, FruR and Fis. AcnB appears to be the main catabolic enzyme in E. coli and AcnA is apparently used in nutritional or oxidative stress [60]. Moreover, overexpression of $a c n B$ has been detected in strains growing on acetate as the only carbon source [60]. Importantly, the transcription level of icd was lower in JM101 grown on glycerol (Table 3). Icd is regulated by phospho/dephosphorylation and synthesizes $\alpha-\mathrm{KG}$ and $\mathrm{NADPH}_{2}$ from ICT. $\alpha-\mathrm{KG}$ is an important metabolite for glutamate biosynthesis (Figure 1). Therefore, a possible flux reduction through Icd is in agreement with the proposed of a reduction of the flux in the lower section of the TCA cycle in JM101. However, this proposal is not in agreement with previous reports of carbon fluxes in other $E$. coli strains where apparently carbon flux through Icd is slightly enhanced when glycerol is used as carbon source as compared to glucose [7]. The fumA and $f u m B$ genes were also overexpressed in JM101, whereas fumC was underexpressed (Table 3); in agreement, FumA was synthesized at higher levels in this strain (Table 4). The fumA gene transcription is positively regulated by Crp and repressed by ArcA and its expression is predominant under aerobic conditions. The fumB gene overexpression was unexpected since this gene is synthesized preferentially on anaerobic conditions. Interestingly, in JM101 grown on glycerol, the frd $A B C D$ operon (encoding the anaerobic fumarate reductase complex) was also overexpressed (Table 3). The fumB gene is positively regulated by FNR, ArcA, Crp and Fur and negatively by Fis and NarL. The frdABCD operon is also positively regulated by FNR and negatively by NarL. Remarkably, the two-component signal system DcuS-DcuR induces transcription of the $d c u B-f u m B$ operon, the frd $A B C D$ operon, and $d c t A$ (C4 compounds transporter) in response to external C4 compounds (SUC, FUM, MAL, and aspartate) [61,62]. Importantly, JM101 grown on glycerol enhanced its $\mu$ when small quantities $(0.005 \mathrm{~g} / \mathrm{L})$ of SUC or MAL were included in the medium (Table 5), suggesting a lower $\mathrm{C} 4$ compounds production when growing on glycerol. From these results it can be concluded that at least another signal is apparently involved in the overexpression of the frd operon and $f u m B$ in this strain grown on glycerol. There was no substantial difference in the expression of the $s d h C D A B$ and $s u c A B C D$ operons in JM101 grown on glycerol as compared to glucose (Table 3). However, the transcription of $l p d A$ was underexpressed. Among other roles, the product of this gene is a component of the SucABCD complex involved in the transformation of $\alpha-K G$ into SUC. These results suggest that a lower carbon flux is probably present in the lower

Table 5 Specific growth rates $(\mu)$ of strain JM101 cultures grown on glycerol when $\mathrm{C} 4$ compounds and amino acids $(0.005 \mathrm{~g} / \mathrm{L})$ were included in the cultures

\begin{tabular}{ll}
\hline Condition & $\boldsymbol{\mu}\left(\mathbf{h}^{-\mathbf{1}}\right)$ \\
\hline JM101 & $0.49(+/-0.01)$ \\
JM101 + L-glutamine & $0.55(+/-0.02)$ \\
JM101 + L-glutamate & $0.48(+/-0.01)$ \\
JM101+ malate & $0.57(+/-0.02)$ \\
JM101+ succinate & $0.55(+/-0.02)$ \\
JM101+ L-arginine & $0.50(+/-0.01)$ \\
JM101+ L-aspartate & $0.52(+/-0.01)$ \\
JM101+ L-lysine & $0.44(+/-0.01)$ \\
JM101+ L-asparagine & $0.50(+/-0.01)$ \\
JM101+ citrate & $0.45(+/-0.01)$ \\
\hline
\end{tabular}


section of the TCA cycle including the Icd and SucA enzymes in strain JM101 (Figure 1). These observations are in agreement with the proposal that a gluconeogenic carbon recycling process is occurring at some degree (acetate conversion to malate and this last compound into PEP), since reducing the transformation of ICT into $\alpha-K G$ and the conversion of this metabolite into SUC-CoA (succinyl coenzyme A) induces carbon diversion through the glyoxylate pathway, whose genes were overexpressed. This proposal in turn allows the conservation of two carbon atoms that are not lost as $\mathrm{CO}_{2}$ in the transformation of ICT into $\alpha-K G$ and from this last compound into SucCoA in the lower section of the TCA cycle, in JM101 grown on glycerol (Table 3, Figure 1).

\section{Indole detection, ribonucleoside metabolism and aromatic compounds production capacity in JM101 grown on glycerol}

TnaA was one of the proteins highly overproduced (17.03 $\mathrm{X}$ ) in JM101 grown on glycerol (Table 4). This protein (tryptophan indole-lyase) converts tryptophan into indole, PYR and ammonia (Figure 1). TnaA specific activity was measured at $1 \mathrm{OD}$ and an increment of $400 \%$ was found in glycerol compared to growth on glucose (Figure 5). Importantly, micromolar concentrations of indole were detected only during growth on glycerol (Figure 6). Indole production was detected when the biomass concentration was around $0.1 \mathrm{~g} / \mathrm{L}$ (0.3 OD). Indole production had two peaks; one at $0.31 \mathrm{~g} / \mathrm{L}$ in the growth curve $(0.83 \mathrm{OD})$ and the other at onset of stationary phase (Figure 6). The JM101 $\Delta$ tnaA derivative with a completely inactivated tnaA gene, was evaluated in bioreactors and compared to JM101 during growth on glycerol. No differences in the specific growth rates were detected between the two strains (data not shown). The final biomass concentration was lower for JM101 $\Delta$ tnaA compared to the parental strain (Figure 7). Surprisingly, the JM101 $\Delta$ tnaA derivative produced acetate $(0.37 \mathrm{~g} / \mathrm{L})$ and small amounts of lactate $(0.037 \mathrm{~g} / \mathrm{L})$, and as expected no indole was detected (Figure 7). Therefore, the question is what could be the role of indole during the growth of strain JM101 on glycerol? Interestingly, when the first indole peak appeared, extracellular concentration of glycerol was about $3 \mathrm{~g} / \mathrm{L}$, indicating that the signal occurred early in the fermentation. The second peak appeared when glycerol was almost exhausted in the media. Therefore, it appears that this signal could be important for continuing exponential growth and to reach a higher biomass at the end of fermentation. It is possible that indole synthesis is part of an adaptive response during different stages of the growth on glycerol cultures. One scenario includes directing the carbon flux into DAHP as a result of the glycerol gluconeogenic metabolism. The synthesis of tryptophan, histidine, NAD and nucleotides (purine and pirymidine) uses 5-phospho-D-ribosyl- $\alpha-1$ - pyrophosphate (PRPP) as a precursor (Figure 1). It appears that about $30-40 \%$ of the synthesized PRPP is apparently used for nucleotide synthesis and about $15 \%$ to produce tryptophan [63]. It is possible that the continuous indole production from tryptophan enhances PRPP demand and this increases DHAP flux that is diverted through the pentose-phosphate pathway (Figure 1). If tryptophan demand is reduced in the strain lacking TnaA, the flux previously diverted to the pentose pathway could be redirected through glycolysis in this derivative. Under this scenario, the TCA cycle was apparently incapable of coping with the extra flux of AcCoA from PYR and this metabolite was converted to acetate and lactate. A second not excluding scenario that could also be involved in the observed indole response is in agreement with the proposed signal role of this metabolite. It is known that indole increases $\mathrm{crl}$ expression at both transcriptional and translational levels. In turn, $\mathrm{Crl}$ stimulates the activity of RpoS, leading to increased transcription rates of the RpoS regulon in the exponential or stationary phase $[41,64]$. Mutants in the $\mathrm{crl}$ or rpoS gene exhibited low synthesis levels of FbaB, TalA, PykF, PfkA, GltA and PoxB [41]. Therefore, one of indole roles could be to activate, through $\mathrm{Crl}$, the RpoS activity and finally the genes implied in the balanced distribution of the carbon flux. In these conditions, a lower production of PoxB and TalA whose genes are transcribed by RpoS in the strain JM101 $\Delta$ tnaA could explain the higher glycolytic flux in this derivative (Figure 1). An additional clue about the distribution of the carbon flux in the pentose-phosphate pathway was the overproduction of Cdd (6.97X), Udp (7.41X) and DeoD (2.08X) in JM101 (Table 4). These proteins are involved in the degradation of nucleobases to bases and pentoses. Under PRPP deficient production conditions, the degradation of ribonucleosides is apparently more important than their phosphorylation to nucleotides [63]. Therefore, these data suggest that in JM101 grown on glycerol, the ribose 5-P (R5P) levels are apparently lower as compared to the strain grown on glucose, thus indicating nucleotide recycling during growth on glycerol.

Indole production also suggested that carbon flux into the aromatic amino acids pathway is increased in JM101 grown on glycerol. In agreement, the RT-qPCR values of most of the genes coding for the common aromatic pathway (aroH, aroF, aroB, aroD, aroE, aroL) were slightly overexpressed (Table 3 ). This capability of strain JM101 to increase carbon flux into the aromatic pathway when grown on glycerol, could explain the high efficiency of production of aromatic compounds of this strain when transformed with plasmid pJLBaroG ${ }^{f b r} t k t A$ that redirects carbon flux into the aromatic pathway [65-67]. The JM101/pJLBaroG ${ }^{f b r} t k t A$ derivative grown on mineral media with glycerol as the sole carbon source, produced aromatic compounds with a high yield (Yaromatics/substrate) of $0.66 \mathrm{mmolC} / \mathrm{mmolC}$, as compared to the of yield of 

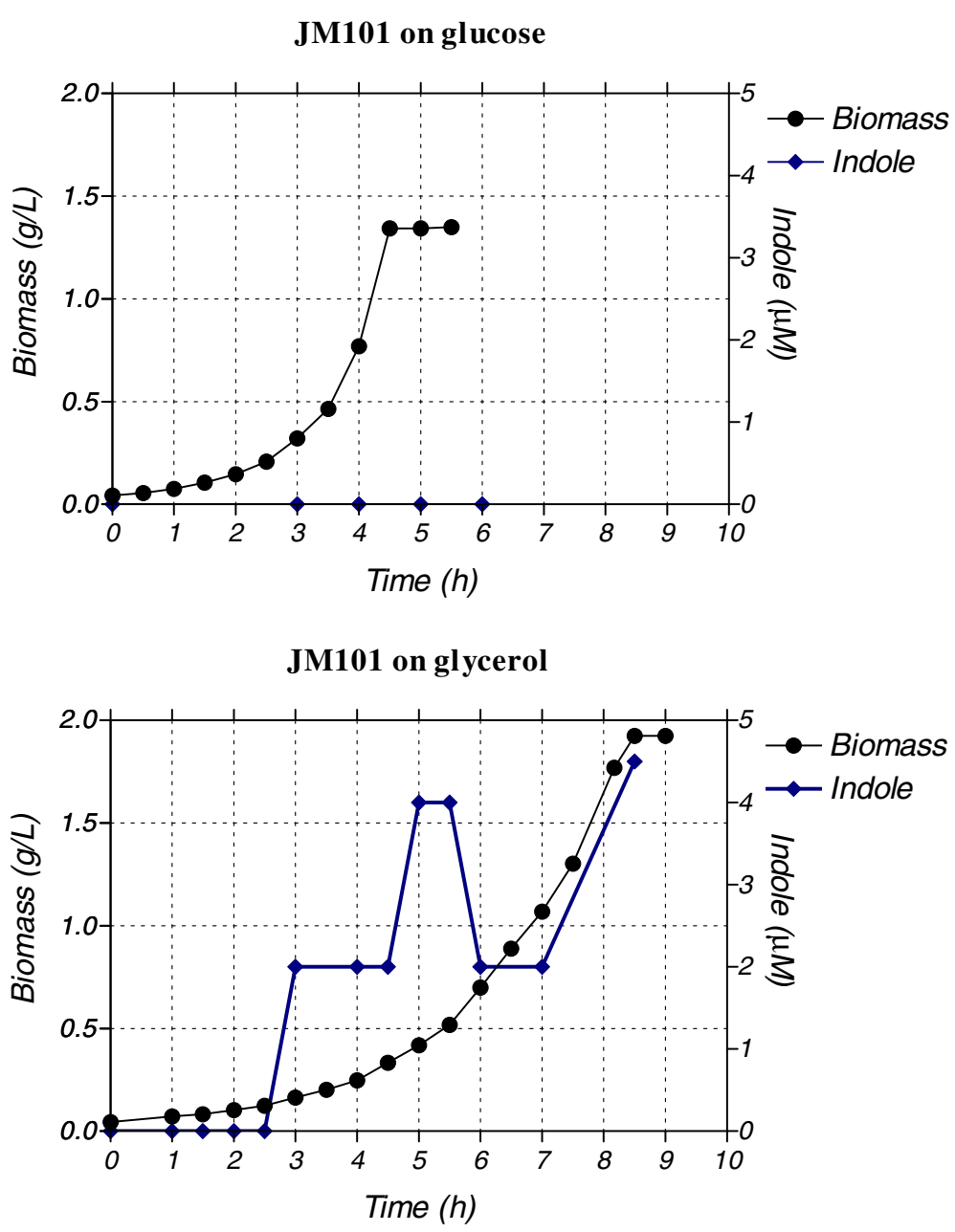

Figure 6 Biomass and indole concentration profiles of strain JM101 grown on glucose or on glycerol.

$0.07 \mathrm{mmolC} / \mathrm{mmolC}$ that was obtained when this derivative was grown on glucose as the sole carbon source (Table 6).

\section{Conclusions}

Overexpression of the genes and overproduction of their coded proteins involved in glycerol uptake and metabolism were detected. These proteins are responsible for the transport and incorporation of glycerol as DHAP, one of the metabolites of the glycolytic pathway. Overexpression of several glycolytic and gluconeogenic genes in the upper part of the glycolytic pathway, especially $f b a A, f b a B, f b p$ and $p g i$, are responsible for the production of G6P from DHAP. Low F1,6P/F6P levels could be the signal for the induction of some of these regulons when strain JM101 is growing on glycerol. This phenomena is reinforced by the differential expression of some genes regulated by Cra which respond to low F1,6P concentrations.

The detected overexpression of the mal/lam and mgl/gal regulons and the overproduction of their coded proteins and some genes regulated by RpoS, indicate that JM101 apparently induced a "carbon stress and carbon scavenging response" when growing on glycerol as the sole carbon source, indicating as reported that this carbohydrate is a poor carbon source. This proposition is in agreement with the involvement of RpoS, the master regulator of stress response in glycerol fermentation, since its inactivation reduced $10 \%$ the $\mu$ and delayed by two hours the growth of JM101 $\operatorname{rpoS}$.

The detected overexpression of poxB, acs, pta, actP, $a c n B$ and the glyoxylate shunt genes (aceBA and $g l c B$ ), some of them transcribed by RpoS, indicates that JM101 is apparently producing and simultaneously consuming acetate when growing on glycerol as the sole carbon 

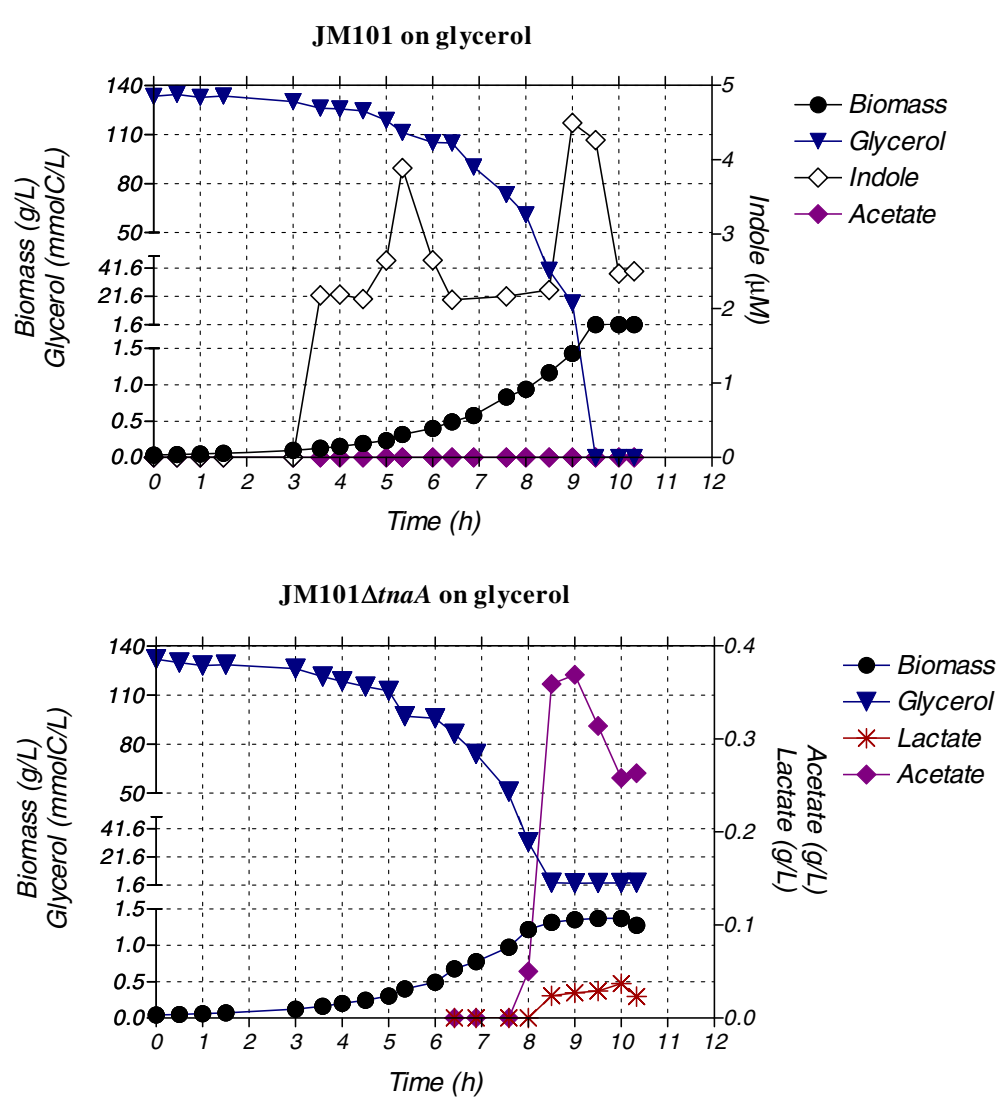

Figure 7 Glycerol consumption patterns and biomass, indole, acetate and lactate production in strains JM101 and JM101 $\Delta$ tnaA.

source. In agreement with this proposal, was the result that no acetate was detected when growing on glycerol, and acetate can be coutilized with glycerol as carbon sources. It has been proposed that when E. coli is growing slowly on glucose apparently reduces the carbon flux through the Pdh system, which yields AcCoA directly from PYR, and diverts part of the carbon flux via PoxB that synthesizes acetate from PYR, with a concomitant reduction of quinones at the membrane. Acetate, is then utilized by Acs and transformed into AcCoA, apparently creating a "carbon acetate recycling" mechanism which is also apparently present in PB11 (a derivative of JM101 lacking PTS) that grows slowly on glucose. Therefore, it appears that in addition to the glycolytic metabolism that is functioning in JM101 when growing on glycerol, carbon scavenging responses are also observed in this strain when it grows on this poor carbon source. Consistent with this proposed metabolic response, in JM101 cultures grown on glycerol as mentioned, no acetate was detected, because this strain probably recycles acetate through the PoxB-Acs-glyoxylate shunt enzymes and is capable of coutilizing glycerol and acetate. In accordance, JM101 derivatives with inactive poxB or $p c k A$ genes accumulated acetate and their specific growth rates were affected. The induction of this mechanism apparently permitted a more efficient carbon utilization and acetate recycling in these growing conditions. In agreement, the downregulation of $i c d$ and $l p d A$ coding for IcdA and LpdA (part of the SucABCD complex), supports the proposition that the carbon flux is reduced through the lower section of the TCA cycle, thus enabling carbon gluconeogenic recycling through the glyoxylate shunt, since $a c e B A$ and $g l c B$ were overexpressed. As a result, if this hypothesis is correct, less carbon should be lost as CO2 in the lower section of the TCA pathway.

In agreement with a reduced TCA cycle during the growth of JM101 on glycerol, it appears that relatively low production of $\mathrm{C} 4$ carbon metabolites occurred, given that the $\mu$ of this strain was enhanced in cultures grown on glycerol when succinate, malate or aminoacids derived from 2-oxoglutarate were added to the fermentation. This supports the hypothesis that when E. coli grows slowly, part of the carbon is recycled, preserved through the glyoxylate shunt and not lost as $\mathrm{CO} 2$ in the TCA cycle.

Indole production in JM101 grown on glycerol indicates an important carbon flux through the aromatic amino acids pathway. Indole is a signaling molecule that activates $\mathrm{Crl}$ for modulating the expression of certain RpoS-Crl 
Table 6 Aromatic compounds yields of strains JM101 and JM101/pJLBaro ${ }^{\text {fbr }}{ }^{t k t} A$ in flask cultures with glucose or glycerol as sole carbon sources

\begin{tabular}{|c|c|c|}
\hline Strains & Carbon source & $\mathrm{Y}_{\text {arom }}(\mathrm{mmolC} / \mathrm{mmolC})$ \\
\hline JM101 & Glucose & Not detected \\
\hline JM101 & Glycerol & $0.25^{-3}\left(+/-0.20^{-4}\right)$ \\
\hline JM101/pJLBaroG ${ }^{f b r} t k t A$ & Glucose & $0.07(+/-0.002)$ \\
\hline JM101/pJLBaroG ${ }^{f b r} t k t A$ & Glycerol & $0.66(+/-0.005)$ \\
\hline
\end{tabular}

(See Methods)

regulons; however, a signaling role of this metabolite is not completely clear at the moment. It has been proposed that the expression of rpoS is not only negatively controlled by cAMP-CRP high levels but also inversely correlated with growth rate. Since glycerol is a relatively poor carbon source, intracellular high levels of cAMP-CRP are expected in JM101. Indole synthesis could stimulate RpoS activity under these non favorable growth conditions. Additional studies should be conducted to gain a better understanding into the role of this signal. Nevertheless, the detected overproduction of Cdd, DeoD, and Upp suggests that the carbon flux through the pentose-phosphate pathway is reduced when glycerol is used as the sole carbon source as compared to the flux when glucose is utilized. It appears that when glycerol is used as the only carbon source, a carbon stress mechanism occurs. In this condition, RpoS regulons could be also indirectly activated by indole, allowing a more adequate response to growth on carbon limited conditions. Importantly, and in agreement with an increased carbon flux through the aromatic pathway growing on glycerol when JM101 is transformed with plasmid pJLBaroG ${ }^{f b r} t k t A$ that redirects and enhances carbon flux into the aromatic pathway, this strain showed a yield increase of aromatic compounds almost 9-fold as compared to the production of these metabolites when glucose is used as the sole carbon source.

Table 7 Strains used in this report

\begin{tabular}{|c|c|c|}
\hline Strains & Relevant characteristics & Source \\
\hline E. coli JM101 & 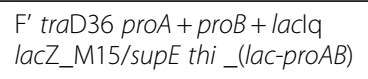 & {$[23,67]$} \\
\hline JM101 $\Delta$ galP & JM101galP:::tc & This work \\
\hline JM101 $\Delta p c k$ & JM101pck::cat & This work \\
\hline JM101 $\Delta p p c$ & JM101ppc.:.cat & This work \\
\hline JM101 $\Delta p y k A$ & JM101pykA::cat & This work \\
\hline JM101 $\Delta p y k F$ & JM101pykF::cat & This work \\
\hline $\mathrm{JM} 101 \Delta \operatorname{tnaA}$ & JM101tnaA::cat & This work \\
\hline $\mathrm{JM} 101 \Delta p o \times B$ & JM101poxB:::cat & [19] \\
\hline JM101 $\Delta r p o S$ & JM101rpoS::tc & [68] \\
\hline JM101/pJLBaroG fbr $t k t A$ & & {$[65,66]$} \\
\hline
\end{tabular}

The transcription levels of most of the measured genes correlated with the detected values of the proteins produced in the analyzed growth conditions, using glycerol as the only carbon source. Also, the specific activities of various measured proteins correlated with these values.

In this contribution we described new features of $E$. coli physiology during the growth on glycerol, as detected through a proteomic-transcriptional study and kineticstoichiometric evaluation of strain JM101 and some isogenic mutants in certain key PEP-PYR genes ( $p \circ x B, p p c$, $p c k A, p y k A$ and $p y k F$ ) and in rpoS. It appears that when glycerol is used as the sole carbon source in addition to the glycolytic metabolism, a carbon stress response occurs that includes carbon scavenging and acetate gluconeogenic carbon recycling responses mediated mainly by RpoS. In addition, this regulator could also be activated by $\mathrm{Crl}$ through indole, allowing a more adequate response to growth on glycerol, a carbon limited condition. The simultaneous utilization of various metabolic redundant alternative mechanisms when growing on glycerol indicates metabolic plasticity of E. coli. Understanding these capacities advances the knowledge on the physiological responses $E$. coli is capable of, and enhances our capacities for developing more advanced metabolic engineering strategies using this bacterium for the production of specific metabolites.

\section{Methods}

\section{Bacterial strains}

Strain JM101 $[23,67]$ and derivatives with specific inactivated genes used in this work are listed in Table 7.

\section{Genetic procedures and recombinant DNA techniques}

PCR reactions were performed using Platinum Taq polymerase accordingly to the manufacturer's recommendations (Invitrogen, USA). Complete inactivation of $p c k$, tnaA, $p y k A$, $p y k F$ and $p p c$ genes was performed by transduction, using P1vir phage grown on strains from the Keio collection [69] carrying these genes inactivated by the Datsenko method [70]. Gene inactivations were confirmed using PCR reactions with specific oligonucleotides (data not shown). Table 8 includes the oligonucleotides utilized in this report.

\section{Growth conditions \\ Batch cultures}

M9 medium, containing (per liter): $6 \mathrm{~g} \mathrm{Na}_{2} \mathrm{HPO}_{4} ; 3 \mathrm{~g}$ $\mathrm{KH}_{2} \mathrm{PO}_{4} ; 0.5 \mathrm{~g} \mathrm{NaCl} ; 1 \mathrm{~g} \mathrm{NH}_{4} \mathrm{Cl} ; 2 \mathrm{mM} \mathrm{MgSO}$; $0.1 \mathrm{mM}$ $\mathrm{CaCl}_{2} ; 0.01 \mathrm{~g}$ Vit $\mathrm{B} 1$, and $2 \mathrm{~g} / \mathrm{L}$ glucose, was utilized for growing the fermentor inocula. A higher concentration of glucose or glycerol $(4 \mathrm{~g} / \mathrm{L}$, approximately $130 \mathrm{mmolC} / \mathrm{L}$, depending on the molecular weight of the carbon source) was utilized in the bioreactors or in $500 \mathrm{~mL}$ shake flask studies, when only one carbon source was employed. When two 
Table 8 Oligonucleotides utilized in this report (gene inactivations and RT-qPCR)

\begin{tabular}{lll}
\hline A. Oligonucleotides used & for the detection of gene inactivations \\
\hline$p c k A$ & pckAFw & CAG GAA TGC GAT TCC ACT CA \\
& pckARv & GTG CAG CGT ATC GTG GAT AA \\
ppc & ppcFw & GCA TCT TAT CCG ACC TAC AC \\
& ppcRv & GCC TGT AGC AGA GTA GAG AA \\
pykA & pykAFw & CTG AAG GAA TCG CGT CGT TTा GA \\
& pykARv & CGG CGG ATG AAT GAA GAA \\
pykF & pykFor & ACA AGC ACA CAT TCC TCT GCA \\
& pykRev & AAA ACA GGA TGC TTC CAT CG \\
tnaA & tnaAFw & TTC TGT AGC CAT CAC CAG AG \\
& tnaARv & CCG GCA AGA TCA ACA GGT AA \\
galP & galpAa & CAT GTA TTA CGC GCC GAA AA \\
& galpAb & TGG CAA GTA CGT TGG TCA GG
\end{tabular}

\begin{tabular}{lll}
\hline \multicolumn{3}{l}{ B. Oligonucleotides used for RT-qPCR assays* } \\
\hline cpdA & cpdAa & CAG CAT TTC GCT GAA GGC AT \\
& cpdaB & GCA TCC TGT AAC GCG CTG TAC \\
$g l p D$ & glpDa & ATG GTG CTG GTA TCG CGG \\
& glpDb & TाT TGA ACT GGC GGA AGA GG \\
$g l p F$ & glpFa & AGG CCA GTG CAT TGC TGA AT \\
& glpFb & ACT GAC CAA AAG ACG CAC CAG \\
$g l p K$ & glpKa & CTC GAC CAT GTG GAA GGC TC \\
& glpKb & ACA CGG CCC TGA GTC ATT TT \\
pntA & pntAa & AAC CAG CGC CGA AGC TAA TT \\
& pntAb & GTA TTC ACA GTT GCC GCC GT \\
udhA & udhAa & AAG GCT GTG ACG ATG GTG TG \\
& udhAb & CGA ATC GGT ATT ACC GGT GC
\end{tabular}

* Oligonucleotide sequences of the remaining utilized genes in Table 3 have been published elsewhere $[12,13,19,20,68]$.

carbon sources were used, the same amount of each carbon source $(2 \mathrm{~g} / \mathrm{L}$, approximately $65 \mathrm{mmolC} / \mathrm{L})$ was employed. When acetate was added as carbon source, the concentration employed was $0.33 \mathrm{~g} / \mathrm{L}$ (approximately $11 \mathrm{mmolC} / \mathrm{L}$ ). Derivative JM101/pJLBaro $G^{f b r}$ tktA $[65,66]$ was also grown in $500 \mathrm{~mL}$ shake flasks using glycerol or glucose as sole carbon sources. IPTG $(0.1 \mathrm{mM})$ was added at the beginning of the fermentation. Tetracycline $(30 \mu \mathrm{g} / \mathrm{mL})$ was included in the medium for plasmid maintenance. Samples from these cultures were obtained during the whole fermentation process. Cells were centrifuged and analyzed for the production of aromatic compounds as described below.

\section{Bioreactor conditions}

Strain JM101 was cultivated in a $1 \mathrm{~L}$ bioreactor (Applikon Biotechnology, Netherlands) with a working volume of $0.75 \mathrm{~L}, 600 \mathrm{rpm}, \mathrm{pH}$ controlled at 7 with $\mathrm{NH}_{4} \mathrm{OH}$ $(2.0 \%)$, and air flow rate of $1 \mathrm{vvm}$, starting at an $\mathrm{OD}_{600}$ of 0.10 and collected when growing in the log phase at an $\mathrm{OD}_{600}$ of 1 .

\section{Kinetic and stoichiometric parameters}

Data represent the average of at least three different cultures. Cell growth was measured by monitoring the optical density at $600 \mathrm{~nm}\left(\mathrm{OD}_{600}\right)$ in a spectrophotometer (Beckman DU700). $\mathrm{OD}_{600}$ was converted into dry cellular weight (biomass concentration) using a standard curve $\left(1 \mathrm{OD}_{600}=0.37 \mathrm{~g} / \mathrm{L}\right.$ of dry cellular weight $)$. Specific growth rates $(\mu)$ were determined by fitting the biomass data versus time to exponential regressions. The biomass yield $(\mathrm{Yx} / \mathrm{s})$ was estimated as the coefficient of linear regression of biomass concentration versus substrate concentration of glucose and glycerol, in grams of biomass $/ \mathrm{mmolC}$ of substrate. The specific carbon consumption rate $\left(\mathrm{q}_{\mathrm{s}}\right)$ was determined as the ratio of $\mu$ to $Y_{x / s}$, according to Monod's model reported elsewhere $[19,71]$. The aromatic compounds yield presented in Table 6 was estimated as the sum of the total production of 3-deoxy-D-arabinoheptulosonate7-phosphate (DAHP), dehydroshikimate (DHS), shikimate (SHIK) and indole in mmolC divided by the total carbon source consumed in mmolC of substrate. L-tryptophan, $\mathrm{L}$-phenylalanine and L-tyrosine were not detected in these fermentations.

\section{Analytical methods}

Metabolite concentrations were determined with an HPLC system (600E quaternary bomb, 717 automatic injector, 2410 refraction index, and 996 photodiode array detectors (Waters, USA). An Aminex HPX-87 H column (300 by $7.8 \mathrm{~mm} ; 9 \mathrm{Am}$ ) (Bio-Rad Laboratories, USA) was used. Running conditions were: mobile phase, $5 \mathrm{mM} \mathrm{H}_{2} \mathrm{SO}_{4}$; flow, $0.5 \mathrm{~mL} / \mathrm{min}$, and temperature, $50^{\circ} \mathrm{C}$. Under these conditions, D-glucose, D-glycerol, DAHP, DHS, SHK, acetate and lactate were detected by refraction index [71]. Indole and the aromatic aminoacids L-tryptophan, L-phenylalanine and L-tyrosine in culture supernatants were quantified using an Agilent 1100 high-performance liquid chromatography system (Agilent Technologies, USA) equipped with a Phenomenex Synergy Hydro RP18 column (150 by $4.6 \mathrm{~mm}$; $4 \mu \mathrm{m})$ attached to an Agilent 1100 electrospray mass spectrometry detection system (Agilent Technologies, USA) [72]. Samples were eluted with $10 \%$ methanol in $0.1 \%$ acetic acid in water at an isocratic flow rate of $0.5 \mathrm{~mL} / \mathrm{min}$. UV detection was performed at $220 \mathrm{~nm}$. A dual solvent system, at a column flow rate of $1.0 \mathrm{~mL} / \mathrm{min}$, was used for separation [73]. Solvent A consisted of $0.1 \%$ trifluoroacetic acid in water, while solvent B was $0.1 \%$ trifluoroacetic acid in acetonitrile. Starting conditions were: $95 \%$ solvent A and $5 \%$ solvent $\mathrm{B}$, the solvent gradient was run for $8 \mathrm{~min}$ and ended at $20 \%$ solvent $A$ and $80 \%$ solvent B. From minutes $8-10$, the ratio was maintained at $20 \%$ solvent $\mathrm{A}$ and $80 \%$ 
solvent B. From minutes 10 to 15 , the ratio was $95 \%$ solvent $A$ and $5 \%$ solvent $B$.

\section{RNA extraction, DNAse treatment of RNA and CDNA synthesis for RT-qPCR analysis Sample management and treatment}

Strain JM101 was grown in different bioreactors using glycerol or glucose (as the control) as carbon sources. After the bioreactor was inoculated at the same optical density (0.1), the culture was monitored to verify and reproduce the $\mu, \mathrm{q}_{\mathrm{s}}$ and $\mathrm{Y}_{\mathrm{x} / \mathrm{s}}$ values. When the fermentation reached $1 \mathrm{OD}, 7 \mathrm{~mL}$ samples were taken directly from the bioreactor using a $1 \mathrm{~mm}$ diameter pipe and collected in $15 \mathrm{~mL}$ cap tubes containing $2 \mathrm{~mL}$ of RNA protect Bacteria Reagent (Quiagen ${ }^{\mathrm{TM}}$, Netherlands) and mixed carefully. After $1 \mathrm{~min}$, the samples were centrifuged at $8,000 \mathrm{rpm}$ for $8 \mathrm{~min}$. The pellet was immediately frozen at $-70^{\circ} \mathrm{C}$ until RNA extraction.

\section{Nucleic acid extraction}

Total RNA was isolated and purified using the hot-phenol method, with some modifications. Samples containing $7 \mathrm{~mL}$ of the collected frozen cells were resuspended in $1 \mathrm{~mL}$ buffer I ( $0.3 \mathrm{M}$ sucrose, $0.1 \mathrm{M}$ sodium acetate), treated with $20 \mu \mathrm{L}$ lysozyme $(10 \mathrm{mg} / \mathrm{mL}$ in $\mathrm{TE}$ buffer $)$ and incubated for $10 \mathrm{~min}$ at room temperature. $2 \mathrm{~mL}$ buffer II (0.01 M sodium acetate, 2\% SDS) were added and the mixture was incubated for $3 \mathrm{~min}$ at $65^{\circ} \mathrm{C}$. The lysate was extracted with $2 \mathrm{~mL}$ of hot phenol and heated for $3 \mathrm{~min}$ at $65^{\circ} \mathrm{C}$. A second extraction with hot phenol was performed without heating the mixtures. Samples were then extracted with $2 \mathrm{~mL}$ of a phenol:chloroform mixture (1:1), precipitated with 0.1 volume of $3 \mathrm{M}$ sodium acetate $(\mathrm{pH}, 5.2)$ and 2.5 volume of ethanol and centrifuged for $15 \mathrm{~min}$ at $4^{\circ} \mathrm{C}, 10,000 \mathrm{rpm}$. Samples were then suspended in a volume containing $300 \mu \mathrm{L}$ of DNAse and RNAse-free water (Ambion Inc, USA) with RNAse inhibitor (Thermo-Scientific, USA) and extracted twice with 1 volume of chloroform. Finally, samples were precipitated as before and suspended in $300 \mu \mathrm{L}$ TE buffer (Ambion Inc, USA). RNA was analyzed on formaldehyde agarose gel for integrity. RNA concentrations were quantified using Nanodrop 2000c (Thermo Scientific, USA); the $260 / 280$ and $260 / 230$ ratios were examined for protein and solvent contamination. For all samples, the 260/ $280 \mathrm{~nm}$ absorbance values were between 1.9-2.0 and in the range of 2.0-2.3 for the $260 / 230 \mathrm{~nm}$ ratio. RNA samples were stored at $-70^{\circ} \mathrm{C}$. For DNAse treatment, total RNA samples were treated with Turbo DNA-free kit (Ambion Inc, USA) at $37^{\circ} \mathrm{C}$ for $30 \mathrm{~min}$, following manufacturer's instructions. To determine whether RNA samples were significantly contaminated with genomic DNA, samples were subjected to conventional PCR with primers for the $\operatorname{arc} A$ gene $[12,13]$. Since these primers were designed to recognize genomic DNA, the presence of a detectable PCR product on an ethidium bromide-stained agarose gel would indicate that the specific RNA sample was contaminated with genomic DNA. PCR reactions were performed with Taq polymerase (Thermo-Scientific, USA). The cycling parameters were: $95^{\circ} \mathrm{C}$ for $5 \mathrm{~min}$; 30 cycles at $95^{\circ} \mathrm{C}$ for $1 \mathrm{~min}, 55^{\circ} \mathrm{C}$ for $1 \mathrm{~min}$ and $72^{\circ} \mathrm{C}$ for $1 \mathrm{~min}$, plus an extension step at $72^{\circ} \mathrm{C}$ for $5 \mathrm{~min}$. Additionally, DNAse-treated RNA samples were used for RT-qPCR analysis of the same $\operatorname{arc} A$ gene, using the appropriate oligonucleotides [ $\operatorname{arc} A \mathrm{a}$ (forward) and $\operatorname{arc} A \mathrm{~b}$ (reverse)] [12,13]. As in the PCR case, all utilized samples did not produce a $101 \mathrm{bp}$ amplimer, indicating that small fragments of genomic DNA contaminating the samples were not present. cDNA was synthesized using RevertAid $^{\mathrm{TM}} \mathrm{H}$ minus first strand cDNA synthesis kit and following the manufacturer's conditions (ThermoScientific., USA). For each reaction, approximately $5 \mu \mathrm{g}$ of RNA and a mixture of $10 \mathrm{pmol} / \mu \mathrm{L}$ of specific DNA reverse primers ( $b$ primers) for each measured gene were used. Nucleotide sequences of these genes have been previously published $[12,13,24,72]$ or are listed in Table 8. cDNA were used as template for RT-qPCR assays.

\section{$R T-q P C R$}

RT-qPCR was performed with the ABI Prism 7000 Sequence Detection System and 7300 Real Time PCR System (Perkin Elmer/Applied Biosystems, USA) using the Maxima $^{\mathrm{R}}$ SYBR Green/ROX qPCR Master Mix (2X) kit (Thermo-Scientific, USA). MicroAmp Optica 96-well reaction plates (Applied Biosystems, USA) and Plate Max ultraclear sealing films (Axygen Biosciences, USA) were used in these experiments. Amplification conditions were $10 \mathrm{~min}$ at $95^{\circ} \mathrm{C}$, followed by a two-step cycle at $95^{\circ} \mathrm{C}$ for $15 \mathrm{~s}$ and $60^{\circ} \mathrm{C}$ for $60 \mathrm{~s}$ for a total of 40 cycles, to finish with a dissociation protocol $\left(95^{\circ} \mathrm{C}\right.$ for $15 \mathrm{~s}, 60^{\circ} \mathrm{C}$ for $1 \mathrm{~min}, 95^{\circ} \mathrm{C}$ for $15 \mathrm{~s}$ and $60^{\circ} \mathrm{C}$ for $15 \mathrm{~s}$ ). DNA sequences of the primers for specific amplifications were designed using the Primer Express software (Applied Biosystems, USA). Some of these have been previously published $[12,13,24]$ and the rest of the sequences are included in Table 8. All RT-qPCR experiments complied with the MIQE guidelines (Minimum Information for Publication of Quantitative Real-Time PCR Experiments) [74,75]. The length of all the utilized oligonucleotides (forward and reverse), was between 18 and 21 nucleotides, with GC\% between 45 to 60 and Tm between 58 to $60^{\circ} \mathrm{C}$. The size of all amplimers was $101 \mathrm{bp}$. The final primer concentration was $0.2 \mu \mathrm{M}$ in a total volume of $12 \mu \mathrm{L}$. Five ng of target cDNA for each gene were added to the reaction mixture, since higher cDNA concentrations $(>10 \mathrm{ng})$ are not in the dynamic range of the reference gene ihfB (see below). Hence the obtained values cannot be correctly normalized for this higher cDNA 
concentration. All experiments were performed at least in triplicate for each gene of each strain, obtaining very similar values (differences $<0.3 \mathrm{SD}$ ). A non-template control reaction mixture was included for each gene and values appeared for all genes, after cycle 31. Standard curves were built to evaluate PCR efficiency and all the genes had $R^{2}$ values above 0.9976 with slopes between -3.4 to-3.7. The quantification technique used to analyze data was the $2^{-\Delta \Delta C q}$ method described by Livak and Schmittgen [76]. Data were normalized using the ihfB gene as an internal control (reference gene). The same reproducible expression level of this gene was detected in all the strains in the conditions in which bacteria were grown and analyzed; this is the most important characteristic that a reference gene should have in accordance with the MIQE guidelines. Supporting information (Additional file 2) presents the ihfB gene values detected for the utilized strains. These results demonstrate the stability of the expression of this reference gene in all the analyzed derivatives for the conditions used in this report and also on previous reports utilizing these strains and other derivatives [12,13,24,74]. For each analyzed gene in all strains, the transcription level of the strain JM101 was considered equal to one, and it was used as control to normalize the data. Therefore, data are reported as relative expression levels, compared to the expression level of the same gene in strain JM101. The results presented in Table 3 are the averages of at least three independent measurements of the RT-qPCR expression values for each gene. Values were obtained from different cDNAs generated from at least five independent bioreactor samples [13].

\section{Enzymatic assays}

For each enzymatic assay, approximately $15 \mathrm{~mL}$ of cultures were harvested and centrifuged at $10,000 \mathrm{rpm}, 4^{\circ} \mathrm{C}$ for $1 \mathrm{~min}$. The pellets were stored at $-20^{\circ} \mathrm{C}$ until the enzymatic assay was performed (not further than two days). Before each assay, the pellets were dissolved in their corresponding enzyme specific buffers (see below). Dissolved cells were disrupted by three sonication steps with $20 \mathrm{~s}$ intervals at 14 milliohms. Cell debris was removed by centrifugation at $10,000 \mathrm{rpm}, 4^{\circ} \mathrm{C}$ for $10 \mathrm{~min}$. Enzymatic assays were performed at $30^{\circ} \mathrm{C}$ using a Thermo Spectronic-Biomate spectrophotometer. The buffer and substrates were mixed in a spectrophotometric cuvette to a final reaction volume of $1 \mathrm{~mL}$. The wavelength and millimolar extinction coefficients for $\mathrm{NADH}_{2}, \mathrm{NADP}^{+}$ and $\mathrm{NADPH}_{2}$ were $340 \mathrm{~nm}$ and $6.22 \mathrm{~cm}^{-1} \mathrm{mM}^{-1}$, respectively. For phenylhydrazine- $\mathrm{HCl}$, the wavelength and millimolar extinction coefficients were $324 \mathrm{~nm}$ and $16.8 \mathrm{~cm}^{-1} \mathrm{mM}^{-1}$, respectively. One unit of specific enzyme activity $(\mathrm{U})$ was defined as the amount of enzyme required to convert 1 mole of substrate into the specific product per minute per milligram of protein. The amount of protein was measured by the Bradford method with bovine serum albumin as the standard [77]. Utilized buffers: Pyruvate kinase (Pyk): $100 \mathrm{mM}$ Tris- $\mathrm{HCl}$ (pH, 7.5), $5 \mathrm{mM}$ ADP, $1 \mathrm{mM}$ DTT, $10 \mathrm{mM} \mathrm{KCl}, 15 \mathrm{mM} \mathrm{MgCl}$, $0.5 \mathrm{mM}$ phosphoenolpyruvate (PEP), $0.25 \mathrm{mM} \mathrm{NADH}_{2}$, $10 \mathrm{U}$ lactate dehydrogenase (Ldh) [78]. PEP carboxylase (Ppc): $60 \mathrm{mM}$ Tris- $\mathrm{HCl}(\mathrm{pH}, 9.0), 10 \mathrm{mM} \mathrm{MgCl}_{2}$, $10 \mathrm{mM} \mathrm{NaHCO}_{3}, 0.15 \mathrm{mM} \mathrm{NADH}_{2}, 5 \mathrm{mM}$ PEP and $2 \mathrm{U}$ of malate dehydrogenase (Mdh) [79]. PEP carboxykinase (PckA): $10 \mathrm{mM}$ TES Buffer (pH, 6.6), $10 \mathrm{mM} \mathrm{MgCl}$, $5 \mathrm{mM} \mathrm{MnCl} 2,1 \mathrm{mM}$ DTT, $10 \mathrm{mM}$ ADP, $75 \mathrm{mM}$ $\mathrm{NaHCO}_{3}, 0.3 \mathrm{mM} \mathrm{NADH}_{2}$ and $20 \mathrm{U}$ of Mdh; in this case one must add cell extract, incubate at $37^{\circ} \mathrm{C}$ for $15 \mathrm{~min}$, then add $10 \mathrm{mM}$ PEP to start the reaction [79]. Malic enzyme (MaeB): $100 \mathrm{mM}$ Tris- $\mathrm{HCl}$ (pH, 7.8), $5 \mathrm{mM} \mathrm{MgCl}_{2}$, $0.6 \mathrm{mM} \mathrm{NADP}{ }^{+}, 40 \mathrm{mM}$ malate [79]. Isocitrate lyase (Icl): $50 \mathrm{mM}$ morpholipepropanesulfonic acid (MOPS; $\mathrm{pH}, 7.3), 1 \mathrm{mM}$ EDTA, $5 \mathrm{mM} \mathrm{MgCl}_{2}, 4 \mathrm{mM}$ phenylhydrazine $\mathrm{HCl}(\mathrm{FH})$ and $12.5 \mathrm{mM} \mathrm{L}$-isocitrate [80]. Isocitrate dehydrogenase (Icdh): $50 \mathrm{mM}$ phosphate buffer $(\mathrm{pH}$ 7.5), $5 \mathrm{mM} \mathrm{MgCl}$, $2 \mathrm{mM} \mathrm{NADP}{ }^{+}, 2.5 \mathrm{mM} \mathrm{D,L}$ isocitrate [81]. Tryptophanase (TnaA): $1000 \mathrm{mM}$ potassium phosphate $(\mathrm{pH}, 8.3), 0.81 \mathrm{mM}$ pyridoxal 5-phosphate, $50 \mathrm{mM}$ L-tryptophan (pH 10.8), trichloroacetic acid $6.1 \mathrm{~N}$, toluene, p-dimethylaminobenzaldehyde solution $5 \%(\mathrm{w} / \mathrm{v})$, hydrochloric acid-alcohol $895 \mathrm{mM}$ [82].

\section{Proteomic analysis}

Protein extraction and two-dimensional gel electrophoresis were carried out as previously described [83]. Gels were dyed in colloidal Coomassie [84] and scanned in a GS-800 densitometer (Bio-Rad Laboratories, CA). Digital images were analyzed and compared using the PDQuest 8.0.1 software from the same company. Each experiment was done in triplicate. Only reproducible phenotypes, with a Student's $t$ test value $\mathrm{p} \leq 0.05$ are shown. Additional file 3 contains other important proteomic parameters. Once the digital image of each gel was compared against the rest, the electrophoretic entities of interest were cut, alkylated, reduced, digested and automatically transferred to a MALDI analysis target by a Proteineer SP II and SP robot using the SPcontrol 3.1.48.0 v software (Bruker Daltonics, Germany), with the aid of a DP Chemicals 96 gel digestion kit (Bruker Daltonics, Germany) and processed in a MALDI-TOF Autoflex (Bruker Daltonics, Germany) to obtain a mass fingerprint. One hundred satisfactory shots were performed in 20 shotsteps; the peak resolution threshold was set at 1500 , the signal/noise ratio of tolerance was 6 , and contaminants were not excluded. The spectrum was annotated by the flexAnalysis $1.2 \mathrm{v}$ SD1 Patch 2 (Bruker Daltonics, Germany). The search engine MASCOT [85] was used to compare the fingerprints against the UNIPROT [86] release 2011-01 database with 
the following parameters: Taxon- Escherichia coli, mass tolerance of up to $200 \mathrm{ppm}$, one miss-cleavage allowed. Carbamidomethyl was the fixed modification and oxidation of methionine the variable modification.

\section{Additional files}

\section{Additional file 1 Central metabolic genes overexpressed or} underexpressed during growth on glycerol as compared to glucose. Certain regulators involved in the expression of these genes are also included.

Additional file $\mathbf{2}$ This figure includes the positions of the amplification curves for the ihfB gene and the Ct values of this gene (see Methods), in the different strains employed in this study. As can be seen, all the amplification curves of the ihfB gene, which has been used as the reference gene, show very similar values. The values presented in the table are from five different fermentations of each strain. These results demonstrate that the same reproducible expression levels are obtained for the ihfB gene in all strains. This is the most important characteristic that a reference gene should have in accordance with the MIQE guidelines $[13,74]$. These results corroborate the stability of the expression of the reference ihfB gene in these strains under the utilized conditions.

Additional file $\mathbf{3}$ This file contains important proteomic parameters for the identified proteins (Gi, Score, Mw, pl, \%cov, EC number and gene ID).

\section{Competing interests}

The authors declare that they have no competing interests.

\section{Acknowledgements}

We thank Magdalena Hernández Ortiz, Mercedes Enzaldo, Aurelia González and Daniela Garcia for their technical assistance. We are also grateful to Paul Gaytán, Jorge Yáñez and Eugenio López for the synthesis of oligonucleotides. This work was supported by Consejo Nacional de Ciencia y Tecnología (Conacyt), Mexico with grants 105782, 83039; FONSEC/SSA/IMSS/ISSSTE/ CONACYT grants 44126, 126793, 167756; DGAPA-PAPIIT, UNAM grants IN213508, IN224709, IN221106, and GAPA-UNAM grant No. IN216210-3.

\section{Author details}

'Departamento de Ingeniería Celular y Biocatálisis, Instituto de Biotecnología, Universidad Nacional Autónoma de México (UNAM), Apdo. Postal 510-3, Cuernavaca, Morelos CP 62250, Mexico. ²Departamento de Medicina Molecular y Bioprocesos, Instituto de Biotecnología, Universidad Nacional Autónoma de México (UNAM), Apdo. Postal 510-3, Cuernavaca, Morelos CP 62250, Mexico. ${ }^{3}$ Programa de Genómica Funcional de Procariotes, Centro de Ciencias Genómicas, Universidad Nacional Autónoma de México (UNAM), Apdo. Postal 565-A, Cuernavaca, Morelos CP 62210, Mexico.

\section{Authors' contributions}

KMG and FB designed the experiments, analyzed the results and wrote the manuscript. KMG carried out the fermentations, samples analysis, gene inactivations, TnaA assay, RNA extraction and samples preparations for proteomic experiments. NF performed RNA purification, CDNA synthesis, RTqPCR experiments and data processing. HMCA carried out Pyk and JM101/ pJLBaro $G^{f b r}$ tktA fermentations, the enzymatic assays, DAHP semipurification. GMB performed the 2-D electrophoresis gel and MALDI-TOF analyses of proteins. GH performed the technical support for DAHP semipurification and HPLC determinations. SE, GG and OTR critically revised the results and the manuscript. All the authors have read and approved the publication of the manuscript.

Received: 15 December 2011 Accepted: 18 April 2012

Published: 18 April 2012

\section{References}

1. Weissenborn DL, Wittekindt N, Larson TJ: Structure and regulation of the glpFK operon encoding glycerol diffusion facilitator and glycerol kinase of Escherichia coli K-12. J Biol Chem 1992, 267:6122-6131.
2. Bisen P, Sanodiya B, Thakur G, Baghel R, Prasad G: Biodiesel production with special emphasis on lipase-catalyzed transesterification. Biotechnol Lett 2010, 32:1019-1030.

3. Vasudevan P, Briggs M: Biodiesel production-current state of the art and challenges. J Ind Microbiol Biotechnol 2008, 35:421-430.

4. Dharmadi Y, Murarka A, Gonzalez R: Anaerobic fermentation of glycerol by Escherichia coli: A new platform for metabolic engineering. Biotechnology \& Bioengeering 2006, 94:821-829.

5. luchi S, Cole ST, Lin EC: Multiple regulatory elements for the glpA operon encoding anaerobic glycerol-3-phosphate dehydrogenase and the $g l p D$ operon encoding aerobic glycerol-3-phosphate dehydrogenase in Escherichia coli: further characterization of respiratory control. J Bacteriol 1990, 172:179-184.

6. Frankel, D.G: Glycolysis. In: Escherichia coli and Salmonella tiphymurium: Cellular and Molecular Biology. 2nd edition. Edited by Neidhardt, F.C. ASM Press, Washington, DC; 1996:189-196.

7. Oh MK, Liao JC: Gene expression profiling by DNA microarrays and metabolic fluxes in Escherichia coli. Biotechnol Prog 2000, 16:278-286.

8. Peng L, Shimizu K: Global metabolic regulation analysis for Escherichia coli K12 based on protein expression by 2-dimensional electrophoresis and enzyme activity measurement. Appl Microbiol Biotechnol 2003, 61:163-178.

9. Notley L, Ferenci T: Induction of RpoS-dependent functions in glucoselimited continuous culture: what level of nutrient limitation induces the stationary phase of Escherichia coli? J Bacteriol 1996, 178:1465-1468.

10. Hua Q, Yang C, Oshima T, Mori H, Shimizu K: Analysis of gene expression in Escherichia coli in response to changes of growth-limiting nutrient in chemostat cultures. Appl Environ Microbiol 2004, 70:2354-2366.

11. Hardiman T, Lemuth K, Keller MA, Reuss M, Siemann-Herzberg M: Topology of the global regulatory network of carbon limitation in Escherichia coli. J Biotechnol 2007, 132:359-374.

12. Flores $N$, Escalante A, de Anda R, Báez-Viveros JL, Merino E, Franco BGeorgellis D, Gosset G, Bolívar F: New insights into the role of sigma factor RpoS as revealed in Escherichia coli strains lacking the phosphoenolpyruvate:carbohydrate phosphotransferase system. Journal of Molecular Microbiology and Biotechnology 2008, 14:176-192.

13. Flores N, Flores S, Escalante A, de Anda R, Leal L, Malpica R, Georgellis D, Gosset G, Bolívar F: Adaptation for fast growth on glucose by differential expression of central carbon metabolism and gal regulon genes in an Escherichia coli strain lacking the phosphoenolpyruvate: carbohydrate phosphotransferase system. Metabolic Engineering 2005, 7:70-87.

14. Storz G, Hengge-Aronis R (Ed): Bacterial stress responses, Chapter 11, page 163. 1st edition. ASM Press, Washington, DC; 2000.

15. Teich A, Meyer S, Lin HY, Andersson L, Enfors SO, Neubauer P: Growth rate related concentration changes of the starvation response regulators RpoS and ppGpp in glucose-limited fed-batch and continuous cultures of Escherichia coli. Biotechnol Prog 1999, 15:123-129.

16. Kayser A, Weber J, Hecht V, Rinas U: Metabolic flux analysis of Escherichia coli in glucose-limited continuous culture. I. Growth-rate-dependent metabolic efficiency at steady state. Microbiology 2005, 151:693-706.

17. Lange $R$, Hengge-Aronis R: Identification of a central regulator of stationaryphase gene expression in Escherichia coli. Mol Microbiol 1991, 5:49-59.

18. Lange R, Hengge-Aronis R: The cellular concentration of the sigma $S$ subunit of RNA polymerase in Escherichia coli is controlled at the levels of transcription, translation, and protein stability. Genes Dev 1994, 8:1600-1612.

19. Flores N, de Anda R, Flores S, Escalante A, Hernández G, Martínez A, Bolívar F: Role of pyruvate oxidase in Escherichia coli strains lacking the phosphoenolpyruvate:carbohydrate phosphotransferase system. J Mol Microbiol Biotechnol 2004, 8:209-221.

20. Olvera L, Mendoza-Vargas A, Flores N, Olvera M, Sigala JC, Gosset G, Bolívar F: Transcription analysis of central metabolism genes in Escherichia coli. Possible roles of sigma38 in their expression, as a response to carbon limitation. PLOS One 2009, 4(e(10)):7466.

21. Flores S, Flores N, de Anda R, Gonzalez A, Escalante A, Gosset G, Bolivar F: Nutrient scavenging stress response in an Escherichia coli strain lacking the phosphoenol pyruvate: carbohydrate phosphotransferase system as explored by gene expression profile. J Mol Microbiol Biotechnol 2005, 10:51-63.

22. Gaal T, Mandel MJ, Silhavy TJ, Gourse RL: Crl facilitates RNA polymerase holoenzyme formation. J Bacteriol 2006, 188:7966-7970.

23. Messing J: A multi-purpose cloning system based on a single-stranded DNA bacteriophage M13. Recombinant DNA Technical Bulletin, NIH Publ 1979, 99:43-48. 
24. Sigala J, Flores SFN, Aguilar C, de Anda R, Gosset G, Bolívar F: Acetate metabolism in Escherichia coli strains lacking phosphoenolpyruvate: carbohydrate phosphotransferase system; evidence of carbon recycling strategies and futile cycles. J Mol Microbiol Biotechnol 2008, 16:224-235.

25. Hengge R: The two-component network and the general stress sigma factor RpoS in Escherichia coli. In Bacterial Signal Transduction: Networks and Drug Targets. 631 edition. Edited by Utsumi R. Springer New York; 2008:40-53.

26. Hengge AR: Regulatory gene expression during entry into stationary phase. Escherichia coli and Salmonella tiphymurium: Cellular and Molecular Biology 1996, 2:1497-1512.

27. Kwon YD, Lee SY, Kim P: A physiology study of Escherichia coli overexpressing phosphoenolpyruvate carboxykinase. Biosci Biotechnol Biochem 2008, 72:1138-1141.

28. Konrberg H: L: The role and control of the glyoxylate cycle in Escherichia coli. Biochem J 1966, 99:1-11.

29. Courtright JB, Henning U: Malate dehydrogenase mutants in Escherichia coli K-12. J Bacteriol 1970, 102:722-728.

30. Fong SS, Palsson BO: Metabolic gene-deletion strains of Escherichia coli evolve to computationally predicted growth phenotypes. Nat Genet 2004, 36:1056-1058

31. Cozzone AJ: Regulation of acetate metabolism by protein phosphorylation in enteric bacteria. Annual Reviews of Microbiology 1998, 52:127-164.

32. Boos W, Shuman H: Maltose/maltodextrin system of Escherichia coli: transport, metabolism, and regulation. Microbiol Mol Biol Rev 1998, 62:204-229.

33. Dippel R, Bergmiller T, Bohm A, Boos W: The maltodextrin system of Escherichia coli: glycogen-derived endogenous induction and osmoregulation. J Bacteriol 2005, 187:8332-8339.

34. Ferenci T: Adaptation to life at micromolar nutrient levels: the regulation of Escherichia coli glucose transport by endoinduction and CAMP. FEMS Microbiol Rev 1996, 18:301-317.

35. Death A, Ferenci T: Between feast and famine: endogenous inducer synthesis in the adaptation of Escherichia coli to growth with limiting carbohydrates. J Bacteriol 1994, 176:5101-5107.

36. Ferenci T: Hungry bacteria. Definition and properties of a nutritional state. Environmental Microbiology 2001, 3:605-609.

37. Liu M, Durfee T, Cabrera JE, Zhao K, Jin DJ, Blattner FR: Global Transcriptional programs reveal a carbon source foraging strategy by Escherichia coli. J Biol Chem 2005, 280:15921-15927.

38. Geanacopoulos M, Adhya S: Functional characterization of roles of GalR and GalS as regulators of the gal regulon. J Bacteriol 1997, 179:228-234.

39. Horváth P, Hunziker A, Erdossy J, Krishna S, Semsey S: Timing of gene transcription in the galactose utilization system of Escherichia coli. J Biol Chem 2010, 285:38062-38068.

40. Hengge-Aronis R: Signal transduction and regulatory mechanisms involved in the control of the sigmaS (RpoS) subunit of RNA polymerase. Microbiol Mol Biol Rev 2002, 66:373-395.

41. Lelong C, Aguiluz K, Luche S, Kuhn L, Garin J, Rabilloud T: The Crl-RpoS regulon of Escherichia coli. Molecular \& Cellular Proteomics 2007, 6:648-659.

42. Pratt LA, Hsing W, Gibson KE, Silhavy TJ: From acids to osmZ: multiple factors influence synthesis of the OmpF and OmpC porins in Escherichia coli. Mol Microbiol 1996, 20:911-917.

43. Ferrario M, Ernsting BR, Borst DW, Wiese DE, Blumenthal RM, Matthews RG: The leucine-responsive regulatory protein of Escherichia coli negatively regulates transcription of ompC and micF and positively regulates translation of ompF. J Bacteriol 1995, 177:103-113.

44. Chen S, Zhang A, Blyn LB, Storz G: micC, a second small-RNA regulator of Omp protein expression in Escherichia coli. J Bacteriol 2004 186:6689-6697.

45. Yoshida T, Qin L, Egger LA, Inouye M: Transcription regulation of ompF and $\mathrm{ompC}$ by a single transcription factor, OmpR. J Biol Chem 2006 281:17114-17123.

46. De la Cruz CE: The complexities of porin genetic regulation. J Mol Microbiol Biotechnol 2010, 18:24-36.

47. Death A, Notley L, Ferenci T: Derepression of LamB protein facilitates outer membrane permeation of carbohydrates into Escherichia coli under conditions of nutrient stress. J Bacteriol 1993, 175:1475-1483.

48. Gosset G: Improvement of Escherichia coli production strains by modification of the phosphoenolpyruvate:sugar phosphotransferase system. Microbial Cell Factories 2005, 4:14.
49. Romeo T, Snoep JL. Glycolysis and flux control. Edited by Bock, A., Curtiss, R., Kaper, J.B., Karp, P.D., Neidhardt,F.C., Nystrom, T., Slauch, J. M., Squires, C.L. and Ussery, D. In: EcoSal-Escherichia coli and Salmonella: Cellular and Molecular Biology. 2005. American Society for Microbiology, Washington, D. C.

50. Lacour S, Landini P: SigmaS-dependent gene expression at the onset of stationary phase in Escherichia coli: function of S-dependent genes and identification of their promoter sequences. J Bacteriol 2004, 186:7186-7195.

51. Mendoza-Vargas A, Olvera L, Olvera M, Grande R, Vega-Alvarado L, Taboada B, Collado-Vides J, Morett E: Genome-wide identification of transcription start sites, promoters and transcription factor binding sites in E. coli. PLOS One 2009, 4(10):e7526.

52. Raman B, Nandakumar MP, Muthuvijayan V, Marten MR: Proteome analysis to assess physiological changes in Escherichia coli grown under glucoselimited fed-batch conditions. Biotechnol Bioeng 2005, 92:384-392.

53. Bledig SA, Ramseier TM, Saier MH Jr: FruR mediates catabolite activation of pyruvate kinase (pykF) gene expression in Escherichia coli. J Bacteriol 1996, 178:280-283.

54. Weber J, Kayser A, Rinas U: Metabolic flux analysis of Escherichia coli in glucose-limited continuous culture. II. Dynamic response to famine and feast, activation of the methylglyoxal pathway and oscillatory behaviour. Microbiology 2005, 151:707-716

55. Gimenez R, Nunez MF, Badia J, Aguilar J, Baldoma L: The gene yjcG, cotranscribed with the gene acs, encodes an acetate permease in Escherichia coli. J Bacteriol 2003, 185:6448-6455.

56. Flores S, Gosset G, Flores N, de Graaf AA, Bolívar F: Analysis of carbon metabolism in Escherichia coli strains with an inactive phosphotransferase system by $13 \mathrm{C}$ labeling and NMR spectroscopy. Metab Eng 2002, 4:124-137.

57. Dong T, Schellhorn H: Control of RpoS in global gene expression of Escherichia coli in minimal media. Molecular Genetics and Genomics 2009, 281:19-33.

58. Oh MK, Rohlin L, Kao KC, Liao JC: Global expression profiling of acetategrown Escherichia coli. J Biol Chem 2002, 277:13175-13183.

59. Cronan J, Subrahmanyam S: FadR, transcriptional co-ordination of metabolic expediency. Mol Microbiol 1998, 29:937-943.

60. Cunningham L, Gruer MJ, Guest JR: Transcriptional regulation of the aconitase genes (acnA and $a c n B$ ) of Escherichia coli. Microbiology 1997, 143:3795-3805.

61. Zientz E, Bongaerts J, Unden G: Fumarate regulation of gene expression in Escherichia coli by the DcuSR (dcuSR Genes) two-component regulatory system. J Bacteriol 1998, 180:5421-5425.

62. Davies SJ, Golby P, Omrani D, Broad SA, Harrington VL, Guest JR, Kelly DJ, Andrews SC: Inactivation and regulation of the aerobic C4-dicarboxylate transport (dctA) gene of Escherichia coli. Journal of Bacteriology 1999, 181:5624-5635.

63. Hove-Jensen B: Mutation in the phosphoribosylpyrophosphate synthetase gene (prs) that results in simultaneous requirements for purine and pyrimidine nucleosides, nicotinamide nucleotide, histidine, and tryptophan in Escherichia coli. J Bacteriol 1988, 170:1148-1152.

64. Dong T, Kirchhof M, Schellhorn H: RpoS regulation of gene expression during exponential growth of Escherichia coli K12. Molecular Genetics and Genomics 2008, 279:267-277.

65. Balderas-Hernandez V, Sabido-Ramos A, Silva P, Cabrera-Valladares N, Hernandez-Chavez G, Baez-Viveros J, Gosset G: Metabolic engineering for improving anthranilate synthesis from glucose in Escherichia coli. Microbial Cell Factories 2009, 8:19.

66. Escalante A, Calderon R, Valdivia A, de Anda R, Hernandez G, Ramirez O, Bolívar F: Metabolic engineering for the production of shikimic acid in an evolved Escherichia coli strain lacking the phosphoenolpyruvate: carbohydrate phosphotransferase system. Microbial Cell Factories 2010, 9:21.

67. Bolívar F, Rodríguez RL, Greene PJ, Betlach MC, Heynker HL, Boyer HW, Crossa JH, Falkow S: Construction and characterization of new cloning vehicles. II. A multipurpose cloning system. Gene 1977, 2:95-113

68. Flores N, Leal L, Sigala JC, De Anda R, Martínez A, Escalante, Bolívar F: Growth recovery on glucose under aerobic conditions of an Escherichia coli strain carrying a phosphoenolpyruvate:carbohydrate phosphotransferase system deletion by inactivating $\operatorname{arc} A$ and overexpressing the genes coding for glucokinase and galactose 
permease. Journal of Molecular Microbiology and Biotechnology 2007, 13:105-116.

69. Baba T, Ara T, Hasegawa M, Takai Y, Okumura Y, Baba M, Datsenko KA, Tomita M, Wanner BL, Mori H: Construction of Escherichia coli K-12 in-frame, single-gene knockout mutants: the Keio collection. Molecular Systems Biology 2006, 2. doi:10.1038/msb4100050.

70. Datsenko KA, Wanner BL: One-step inactivation of chromosomal genes in Escherichia coli K-12 using PCR products. Proc Natl Acad Sci 2000, 97:6640-6645.

71. Martínez K, de Anda R, Hernández G, Escalante A, Gosset G, Ramírez OT, Bolivar F: Coutilization of glucose and glycerol enhances the production of aromatic compounds in an Escherichia coli strain lacking the phosphoenolpyruvate: carbohydrate phosphotransferase system. Microbial Cell Factories 2008, 7:1.

72. Chávez-Béjar MI, Lara AR, López H, Hernández-Chávez G, Martínez A, Ramírez OT, Bolívar F, Gosset G: Metabolic engineering of Escherichia coli for L-tyrosine production by expression of genes coding for the chorismate mutase domain of the native chorismate mutase-prephenate dehydratase and a cyclohexadienyl dehydrogenase from Zymomonas mobilis. Appl Environ Microbiol 2008, 74:3284-3290.

73. Xue Z, McCluskey M, Cantera K, Ben-Bassat A, Sariaslani FS, Huang L: Improved production of p-hydroxycinnamic acid from tyrosine using a novel thermostable phenylalanine/tyrosine ammonia lyase enzyme. Enzyme Microb Technol 2007, 42:58-64.

74. Bustin SA, Benes V, Garson JA, Hellemans J, Huggett J, Kubista M, Mueller R, Nolan T, Pfaffl MW, Shipley GL, Vandesompele J, Wittwer CT: The MIQE guidelines: minimum information for publication of quantitative realtime PCR experiments. Clinical Chemistry 2009, 55:611-622.

75. Taylor S, Wakem M, Dijkman G, Alsarraj M, Nguyen M: A practical approach to RT-qPCR publishing data that conform to the MIQE guidelines. Methods 2010, 50:51-S5.

76. Livak KJ, Schmittgen TD: Analysis of relative gene expression data using real-time quantitative PCR and the 2-[Delta][Delta]CT method. Methods 2001, 25:402-408.

77. Kruger NJ: The Bradford method for protein quantitation. In: Basic Protein and Peptide Protocols. 32 edition. Edited by Walker, J.M. Humana Press Inc., Totowa, NJ; 1994:9-15

78. Sridhar J, Eiteman MA, Wiegel JW: Elucidation of enzymes in fermentation pathways used by Clostridium thermosuccinogenes growing on inulin. Appl Environ Microbiol 2000, 66:246-251.

79. der Werf MJV, Guettler MV, Jain MK, Zeikus JG: Environmental and physiological factors affecting the succinate product ratio during carbohydrate fermentation by Actinobacillus sp. 130Z. Arch Microbiol 1997, 167:332-342.

80. Ramírez-Trujillo JA, Encarnación S, Salazar E, de los Santos AG, Dunn MF, Emerich DW, Calva E, Hernández-Lucas I: Functional characterization of the Sinorhizobium meliloti acetate metabolism genes aceA, SMc00767, and glcB. Journal of Bacteriology 2007, 189:5875-5884.

81. Aoshima M, Ishii M, Yamagishi A, Oshima T, Igarashi Y: Metabolic characteristics of an isocitrate dehydrogenase defective derivative of Escherichia coli BL21(DE3). Biotechnol Bioeng 2003, 84:732-737.

82. Boctor FN, Ragher HH, Kamel MY, Hamed RR: A colorimetric method for the determination of indole, and its application to assay of tryptophanase. Anal Biochem 1978, 86:457-462.

83. Salazar E, Díaz-Mejía JJ, Moreno-Hagelsieb G, Martínez-Batallar G, Mora Y, Mora J, Encarnación S: Characterization of the NifA-RpoN regulon in Rhizobium etli in free life and in symbiosis with Phaseolus vulgaris. Applied Environmental Microbiology 2010, 76:4510-4520.

84. Higareda-Almaraz J, Enríquez-Gasca M, Hernández-Ortiz M, Resendis-Antonio O, Encarnación-Guevara S: Proteomic patterns of cervical cancer cell lines, a network perspective. BMC Syst Biol 2011, 5:96

85. Perkins DN, Pappin DJ, Creasy DM, Cottrell JS: Probability-based protein identification by searching sequence databases using mass spectrometry data. Electrophoresis 1999, 20:3551-3567.

86. The UniProt Consortium: The universal protein resource (UniProt). Nucleic Acids Res 2008, 36:D190-D195.

doi:10.1186/1475-2859-11-46

Cite this article as: Martínez-Gómez et al: New insights into Escherichia coli metabolism: carbon scavenging, acetate metabolism and carbon recycling responses during growth on glycerol. Microbial Cell Factories 2012, 11:46.

\section{Submit your next manuscript to BioMed Central and take full advantage of:}

- Convenient online submission

- Thorough peer review

- No space constraints or color figure charges

- Immediate publication on acceptance

- Inclusion in PubMed, CAS, Scopus and Google Scholar

- Research which is freely available for redistribution 